\title{
Serotonin-specific neurons differentiated from human iPSCs form distinct subtypes with synaptic protein assembly
}

\author{
Charline Jansch ${ }^{1} \cdot$ Georg C. Ziegler ${ }^{1,2}\left([) \cdot\right.$ Andrea Forero $^{1} \cdot$ Sina Gredy ${ }^{3,4} \cdot$ Sina Wäldchen $^{5} \cdot$ Maria Rosaria Vitale $^{1,4}$. \\ Evgeniy Svirin ${ }^{1,4}$. Johanna E. M. Zöller ${ }^{1,6}$. Jonas Waider ${ }^{1} \cdot$ Katharina Günther $^{7,8} \cdot$ Frank Edenhofer $^{7} \cdot$ Markus Sauer $^{5}$. \\ Erhard Wischmeyer ${ }^{1,3} \cdot$ Klaus-Peter Lesch $^{1,4,6}$
}

Received: 21 November 2019 / Accepted: 10 January 2021 / Published online: 9 February 2021

(c) The Author(s) 2021

\begin{abstract}
Human induced pluripotent stem cells (hiPSCs) have revolutionized the generation of experimental disease models, but the development of protocols for the differentiation of functionally active neuronal subtypes with defined specification is still in its infancy. While dysfunction of the brain serotonin (5-HT) system has been implicated in the etiology of various neuropsychiatric disorders, investigation of functional human 5-HT specific neurons in vitro has been restricted by technical limitations. We describe an efficient generation of functionally active neurons from hiPSCs displaying 5-HT specification by modification of a previously reported protocol. Furthermore, 5-HT specific neurons were characterized using high-end fluorescence imaging including super-resolution microscopy in combination with electrophysiological techniques. Differentiated hiPSCs synthesize 5-HT, express specific markers, such as tryptophan hydroxylase 2 and 5-HT transporter, and exhibit an electrophysiological signature characteristic of serotonergic neurons, with spontaneous rhythmic activities, broad action potentials and large afterhyperpolarization potentials. 5-HT specific neurons form synapses reflected by the expression of pre- and postsynaptic proteins, such as Bassoon and Homer. The distribution pattern of Bassoon, a marker of the active zone along the soma and extensions of neurons, indicates functionality via volume transmission. Among the high percentage of 5-HT specific neurons ( $42 \%$ ), a subpopulation of $\mathrm{CDH} 13$ + cells presumably designates dorsal raphe neurons. hiPSC-derived 5-HT specific neuronal cell cultures reflect the heterogeneous nature of dorsal and median raphe nuclei and may facilitate examining the association of serotonergic neuron subpopulations with neuropsychiatric disorders.
\end{abstract}

Keywords Human induced pluripotent stem cell (hiPSC) - Serotonin-specific neurons $\cdot$ Median and dorsal raphe $\cdot$ Synapse formation $\cdot$ Cadherin-13 (CDH13) $\cdot$ Neuropsychiatric disorders

\section{Introduction}

A complex interplay of multiple genes and environmental factors causes abnormalities in brain development increasing the risk for neurodevelopmental and psychiatric disorders (Lesch et al. 2011; Wang et al. 2009). These diseases are associated with alterations at both structural and functional

Charline Jansch and Georg C. Ziegler have contributed equally to this work.

Georg C. Ziegler

ziegler_g@ukw.de

$\triangle$ Klaus-Peter Lesch

kplesch@mail.uni-wuerzburg.de

https://publons.com/researcher/1759316

Extended author information available on the last page of the article brain levels implicating, among others, monoaminergic systems. Accordingly, dysregulation of serotonin (5-HT), norepinephrine, and dopamine signaling in the brain have been linked to the pathogenesis of affective and psychotic disorders (Ashok et al. 2017; Lissemore et al. 2018; Siuta et al. 2010). 5-HT is released throughout the entire central nervous system (CNS) and exerts its action by modulation of sensory processing, cognitive control, and emotion regulation. Furthermore, 5-HT regulates developmental processes, such as cell proliferation, migration, differentiation, maturation, and survival (Lesch and Waider 2012). Different 5-HT receptors promote neural expansion and facilitate neuronal interactions (Banasr et al. 2003; Zhang 2003). Most of the studies published on the biophysical characteristics of the 5-HT system were conducted in animal models (Gutknecht et al. 2008; Jones et al. 2015; Norton et al. 2008; Saigal 
et al. 2013; Waider et al. 2017). The molecular and cellular intricacies of 5-HT signaling in humans and their impact on health and disease, however, are still largely unknown (for review, Daubert and Condron 2010; Erzurumlu and Gaspar 2012; Garbarino et al. 2019; Gaspar et al. 2003; Lesch and Waider 2012; Marazziti 2017).

The brain 5-HT system originates from the raphe nuclei. These nuclei extend along the midline of the brainstem and are separated into a rostral group, responsible for the widespread innervation of numerous brain regions, and a caudal group, which projects to the spinal cord (Alonso et al. 2013; Kiyasova and Gaspar 2011; Muzerelle et al. 2016). During development, ventral rostral hindbrain progenitors arise from rhombomeric (r) segments 2-3 and generate median raphe 5-HT specific neurons (Alonso et al. 2013; Bang et al. 2012), whereas the dorsal raphe nucleus arises from rhombomere 1 (Jensen et al. 2008). The allocation of 5-HT specific neurons to a median and dorsal raphe origin is of clinical interest as the two raphe nuclei play differential roles in social and addictive behavior (Balazsfi et al. 2018; Verheij et al. 2018).

Cadherin-13 (CDH13) is implicated in multiple neurodevelopmental disorders, such as autism spectrum disorders (Sanders et al. 2011, 2015), attention-deficit/hyperactivity disorder (ADHD) (Lasky-Su et al. 2008; Lesch et al. 2008; Neale et al. 2010), major depressive disorder (Edwards et al. 2012), and substance use disorders (Hart et al. 2012; Treutlein et al. 2009; Uhl et al. 2008). As a negative regulator of axonal outgrowth (Fredette et al. 1996) CDH13 contributes to the development of the raphe nuclei. During the development of the mouse 5-HT system, CDH13 is enriched in the lateral wing of the dorsal raphe nucleus, whereas the median raphe is spared. CDH13 influences cell density and guides outgrowth of serotonergic neurons to the prefrontal cortex thereby influencing impulsive behavior as well as learning and memory (Forero et al. 2020; Forero et al. 2017).

The reprogramming of human adult fibroblasts into pluripotent stem cells by ectopic expression of four transcription factors revolutionized stem cell research both in terms of ethical concerns and routine applicability (Ardhanareeswaran et al. 2017; Brennand et al. 2012; Kaiser and Feng 2015). Human induced pluripotent stem cells (hiPSCs) are now a widely employed tool to generate patient-derived cell, tissue, and organoid models with the potential to reveal molecular mechanisms underlying the pathogenesis of neurodevelopmental disorders (Brennand et al. 2011; Halevy et al. 2015; Mariani et al. 2015). The successful generation of patient-derived disease models for neurodevelopmental disorders depends on reliable and robust methods for the differentiation of neuronal subtypes from hiPSCs. This field of research requires replication and refinement of previously established differentiation approaches (McNeill et al. 2020). Several protocols describe the generation of specific neuronal subtypes, such as motor neurons (Intoh et al. 2016), dopamine (Fedele et al. 2017; Kirkeby et al. 2017; Kriks et al. 2011; Sanchez-Danes et al. 2012; Suzuki et al. 2017; Tofoli et al. 2019), glutamate (Cao et al. 2017; Gunhanlar et al. 2018; Shi et al. 2012), and $\gamma$-aminobutyric acid (GABA)-specific (Merkle et al. 2015; Yang et al. 2017) neurons while relatively little is known about the differentiation into serotonergic neurons ( $\mathrm{Lu}$ et al. 2016; Vadodaria et al. 2016).

A previously reported method for the generation of 5-HT specific neurons from hiPSCs provides mainly median raphe 5-HT specific neurons ( $\mathrm{Lu}$ et al. 2016). The protocol relies on the addition of small molecules which initiate a timeand concentration-dependent recapitulation of neurodevelopmental pathways by patterning hindbrain development (Lu et al. 2016). Here, we aimed to replicate this hindbrain differentiation method for the generation of 5-HT specific neurons from hiPSCs to provide an in-depth characterization of these cells. We validated the successful differentiation of serotonergic neurons by specific markers including tryptophan hydroxylase 2 (TPH2), 5-HT transporter (5-HTT), and 5-HT. Additionally, we assessed functionality of 5-HT specific neurons by electrophysiological recordings in the longitudinal course over 6 weeks. Finally, we identified subpopulations of 5-HT specific neurons by immunocytochemical analyses of $\mathrm{CDH} 13$ expression and examined their ability to form interneuronal connections by super-resolution imaging of synaptic markers.

\section{Material and methods}

\section{Reprogramming of human fibroblasts into hiPSCs}

The hiPSC line UKWMPi001-B was generated by reprogramming fibroblasts of a healthy donor using the CytoTuneiPS Reprogramming Kit 2.0 (Thermo Fisher Scientific, Waltham, MA, USA) as previously described (Jansch et al. 2018). For a detailed description of the reprogramming procedure, see SM. A further hiPSC line JMUi001-A (Kwok et al. 2018) reprogrammed by a lentiviral vector (Somers et al. 2010) from normal human dermal fibroblasts (NHDFs, Promocell) was used to verify the establishment of the differentiation procedure in terms of the expression of 5-HT specific markers and CDH13, as well as the electrophysiological signature of the generated 5-HT specific neurons (data not shown). Pluripotent capacity of both hiPSC lines was assessed by immunostaining (OCT3, SSEA-4, TRA-1$60)$ and FACS (TRA-1-60) or qRT-PCR (NANOG, OCT3, $R E X I$ ) of pluripotency factors, and by spontaneous differentiation into all three germ layers after embryoid body (EB) formation. Chromosomal integrity was confirmed by karyotyping (g-banding)(Fig. S1). hiPSCs were subsequently cultivated as described in Supplementary Material (SM). 


\section{Differentiation of hiPSCs into 5-HT specific neurons}

iPSC colonies were maintained on Matrigel-coated 6-well plates in StemMACS ${ }^{\mathrm{TM}}$ iPS-Brew XF (Miltenyi Biotec) and neuralized using a modified version of a previously described hindbrain differentiation protocol (Fig. 1A) (Lu et al. 2016). Briefly, hiPSCs were detached with Accutase and transferred to an ultra-low attachment plate (Corning) in neural induction medium (DMEM-F12:Neurobasal $(1: 1), 1 \times \mathrm{N} 2$ supplement (Invitrogen, Carlsbad, CA, USA), $1 \times$ B27 supplement (Invitrogen), $1.4 \mu \mathrm{M}$ CHIR 99021 (Axon Medchem, Groningen, The Netherlands), $2 \mu \mathrm{M}$ DMH1 (Tocris Bioscience, Bristol, U.K.) and $2 \mu \mathrm{M} \mathrm{SB} 431542$ (Miltenyi Biotec)) to generate EBs. After 7 days, medium-sized (200-300 $\mu \mathrm{m}$ in diameter), free-floating EBs were transferred to poly-ornithine (PO, $20 \mu \mathrm{g} / \mathrm{ml}$, Merck Millipore)- and laminin $(10 \mu \mathrm{g} / \mathrm{ml}$, BioLamina, Sundbyberg, Sweden)-coated 6-well plates (15 EBs/well) in neural progenitor cell (NPC) medium containing neural induction medium and SHH C25II (1000 ng/ml; R\&D Systems, Minneapolis, MN, USA) for ventralization of rostral hindbrain progenitors. Rosette-forming EBs were manually isolated and plated on PO-laminin-coated 6-well plates in the same NPC medium containing SHH C25II (1000 ng/ml) and FGF4 (10 ng/ml; Peprotech, Hamburg, Germany) to specify the serotonergic fate of NPCs for one further week. The medium was changed every other day. At the beginning of week 4 of differentiation NPCs showing the right morphology (small, tightly packed cells organized in neural tube-like structures) were selected, dissociated using Accutase for $3 \mathrm{~min}$ and finally plated for neuronal differentiation (4-8 weeks) at lower densities $\left(3 \times 10^{4}\right.$ cells $\left./ 1.9 \mathrm{~cm}^{2}\right)$ onto PO-laminin-coated glass coverslips for electrophysiological analysis, on poly-D-lysine (PDL)-laminin-coated 8 -chamber slides $\left(2 \times 10^{4}\right.$ cells $\left./ 0.8 \mathrm{~cm}^{2}\right)$ for immunofluorescence (IF) stainings, and on PO-laminin-coated glass slides $\left(1 \times 10^{5}\right.$ cells/slide) for $d$ STORM analyses in neuronal maturation medium (NMM). NMM was composed of brainderived neurotrophic factor (BDNF, $10 \mathrm{ng} / \mathrm{ml}$, Peprotech), glial cell-derived neurotrophic factor $(10 \mathrm{ng} / \mathrm{ml}$, Peprotech), ascorbic acid (200 nM, Sigma-Aldrich), laminin ( $1 \mu \mathrm{g} / \mathrm{ml}$, Biolamina), $2.5 \mu \mathrm{M}$ DAPT, $10 \mathrm{ng} / \mathrm{ml}$ insulin-like growth factor-I (IGF-I), and $1 \mathrm{ng} / \mathrm{ml}$ transforming growth factor $\beta 3$ (all from PeproTech) in Neurobasal supplemented with $\mathrm{N} 2+\mathrm{B} 27$. The medium was changed every third day for 4-8 weeks. Successful generation of rostral hindbrain NPCs after 1 week (Fig. 1B a-b), ventral rostral hindbrain NPCs after 2 weeks (Fig. 1B c-d), and ventral rostral hindbrain NPCs with definite serotonergic fate after 3 weeks (Fig. 1B e) was indicated by double immunostainings for respective neurodevelopmental markers. Maturation of these NPCs into 5 -HT specific neurons after 5 weeks of neuronal maturation was demonstrated by IF stainings for TPH2, 5-HT, and 5-HTT (Fig. 2B).

\section{Imaging techniques}

\section{Epifluorescence}

Cells were grown, fixed, and labelled on PDL-laminincoated 8 -chamber slides $\left(20 \times 10^{3}\right.$ cells/well; Corning) as described in SM. Images of differentiation markers in NPCs (Fig. 1B), and images of neural maturation, and glia cell markers (Fig. 2A) were obtained using an Olympus motorized inverted system microscope IX81, an X-Cite fluorescence illuminator, and an XM10 camera (all Olympus, Leinfelden-Echterdingen, Germany). Pictures were taken at $10 \times, 20 \times$, and/or $40 \times$ magnifications through the exposure channels for Alexa Fluor 488, Alexa Fluor 555, Alexa Fluor 647 , and DAPI. Images were then processed using software CellSense (Olympus), and corrected for contrast and brightness using ImageJ v2.0.0 (Schneider et al. 2012). To further elucidate the role of $\mathrm{CDH} 13$ for the developing human 5-HT system we performed double immunostainings for $\mathrm{CDH} 13$ with Nestin as general NPC marker, HOXA2 as rostral hindbrain marker, and NKX2.2 and NKX6.1 as ventral rostral hindbrain markers in 3 week old NPCs (Fig. S2A), and reassessed CDH13 immunoreactivity after 8 weeks of neuronal maturation in $B \mathrm{TUB}+/ \mathrm{TPH} 2+$ cells (Fig. S2B). The proportion of $\mathrm{CDH} 13+$ cells among Nestin +/HOXA2 + NPCs and among BTUBIII +/TPH2 + double-positive cells was counted in images from four randomly selected areas per coverslip ( $n=4$ coverslips per independent differentiation) using Image J.

\section{Confocal microscopy}

Cells were grown, fixed, and labelled on PDL-laminincoated 8 -chamber slides (Corning; $20 \times 10^{3}$ cells/well, for detailed protocol, see SM). Images of neuronal subtype markers were generated using a FluoView FV1000 confocal microscope (Olympus) with a $20 \times$ UPlanSAPO, NA 0.75 (air) objective. Stack images were taken by laser illumination at $561 \mathrm{~nm}$ (Alexa Fluor 555), $488 \mathrm{~nm}$ (Alexa Fluor 488), and $405 \mathrm{~nm}$ (DAPI). 12-bit raw images were processed with the imaging software Fluoview, version 4.1.a (Olympus).

\section{Structured illumination microscopy (SIM)}

SIM microscopy was performed as previously described (Forero et al. 2017). Cells were grown, fixed, and labelled on PO-laminin-coated 24 -well plates $\left(3 \times 10^{4}\right.$ cells/well $)$ as described in SM. Images of $\mathrm{CDH} 13$ expression in $\mathrm{TPH} 2+$ neurons were captured with a commercial inverted SIM microscope (Zeiss ELYRA, Carl Zeiss Microscopy, Oberkochen, Germany) using an oil-immersion objective (Plan-Apochromat 6x/1.4 Oil Dic M27) (Gustafsson 2000; 
A

Human iPSCs Embryoid bodies Neural rosettes Neural tube-like structures Neurons

Ventral rostral hindbrain NPCs $\quad$ 5-HT NPCS
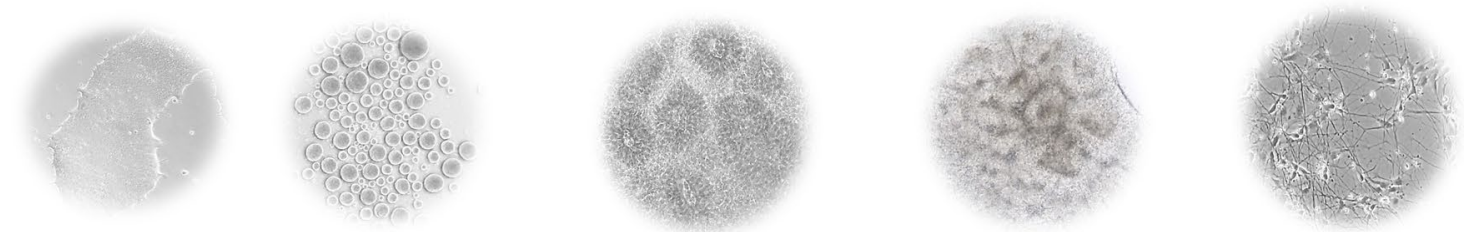

week

2

3

4-11

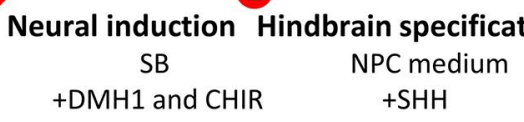

$\mathrm{B}$

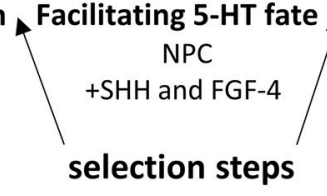

Neuronal maturation

GDNF + BDNF + CAMP
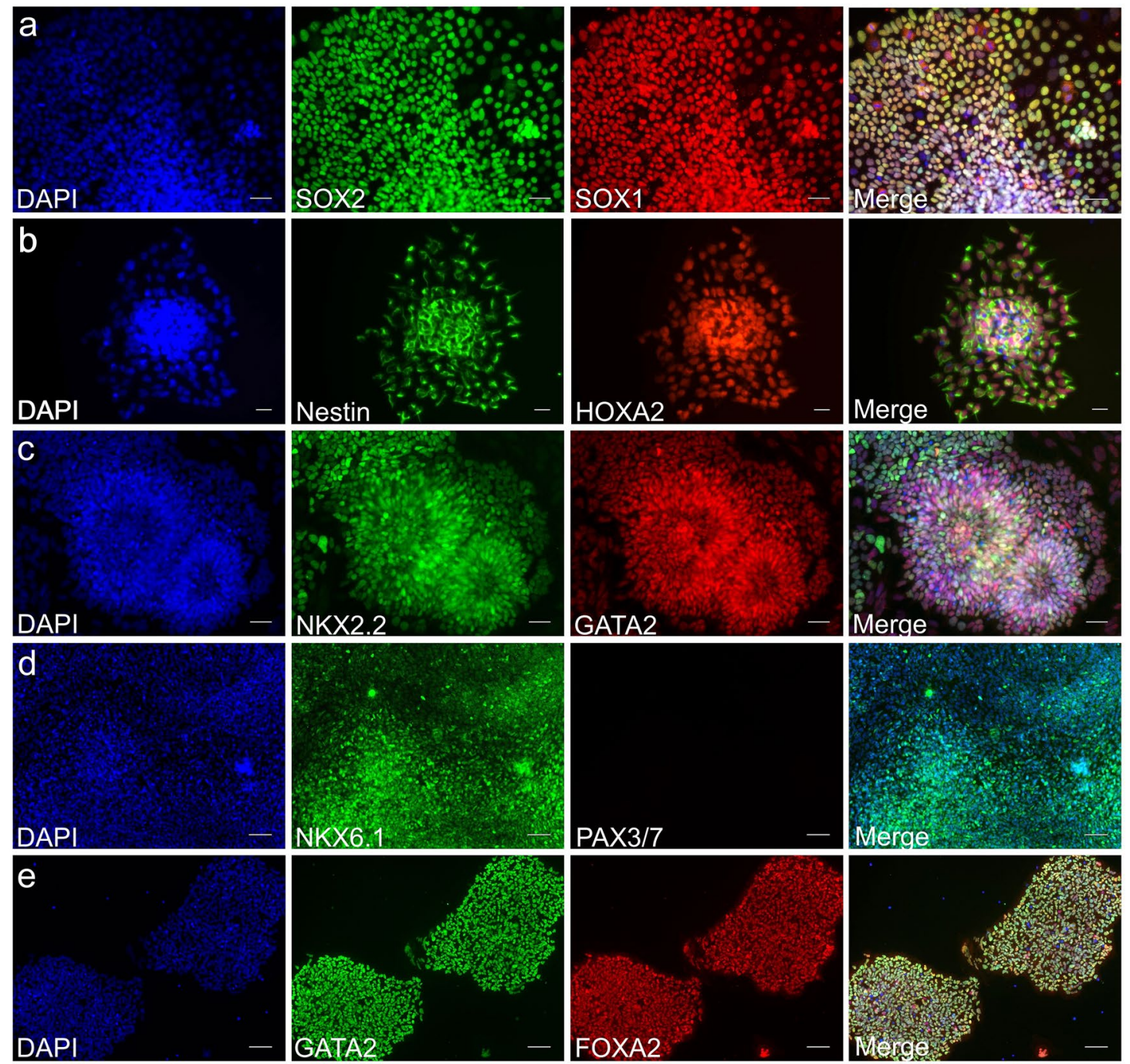

e
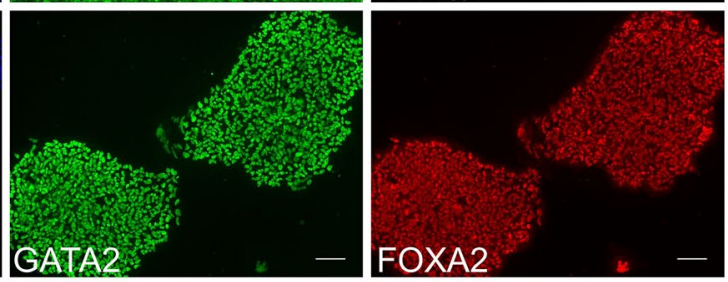
४Fig. 1 Differentiation of hiPSCs into 5-HT specific progenitors. A Scheme of the differentiation protocol describing the generation of hiPSCs-derived 5-HT specific neurons. B Generation of 5-HT specific progenitors illustrated by epifluorescence microscopy. a, b Specification of rostral hindbrain progenitors. After 1 week of neural induction cells were stained for typical neural markers, such as Nestin, SOX2, and SOX1. High expression level of HOXA2, a marker for hindbrain progenitors, was additionally found during that time point in these cells. c, d Ventralization of cells was shown by positive IF staining of NKX2.2, NKX6.1, GATA2 and negative staining of PAX3/7, when treated with $1000 \mathrm{ng} / \mathrm{ml} \mathrm{SHH}$ for 1 week. e Ventralized rostral progenitors were treated with FGF4 for one further week to generate 5-HT progenitors with immunoreactivity for GATA2 and FOXA2. Scale bar: $50 \mu \mathrm{m}(\mathbf{a}-\mathbf{c}), 100 \mu \mathrm{m}(\mathbf{d}, \mathbf{e})$. Cell nuclei were counterstained with DAPI, and Alexa Fluor 488 (SOX2, Nestin, NKX2.2, NKX6.1, GATA2), and Alexa Fluor 555 (SOX1, HOXA2, GATA2, PAX3/7, FOXA2) were used to visualize target proteins. 5-HT specific progenitor differentiation was verified using the JMUi001-A iPS line (data not shown)

Wegel et al. 2016). Excitation of the fluorophores was performed by laser illumination at $642 \mathrm{~nm}$ (Alexa Fluor 647), $561 \mathrm{~nm}$ (Alexa Fluor 555), $488 \mathrm{~nm}$ (Alexa Fluor 488), and $405 \mathrm{~nm}$ (DAPI), and fluorescence light was filtered by appropriate detection filters: LP 655 (Alexa Fluor 647), BP 570-620 + LP 750 (Alexa Fluor 555), BP 495-550 + LP 750 (Alexa Fluor 488), and BP 420-480 + LP 750 (DAPI).

\section{Direct stochastic optical reconstruction microscopy (dSTORM)}

For $d$ STORM, hiPSC-derived neurons were grown, fixed, and labelled on PO-laminin-coated glass bottom dishes (ibidi, Munich, Germany) as described in SM. For fluorophore photo switching, a buffer containing $1 \%$ glucose and $100 \mathrm{mM} \beta$-mercaptoethylamine (Sigma-Aldrich) in PBS adjusted to a $\mathrm{pH}$ of 8.0 was used. $d \mathrm{STORM}$ was performed on a wide-field setup for localization microscopy (van de Linde et al. 2011). A diode laser with a wavelength of $640 \mathrm{~nm}$ (iBeam smart, TOPTICA Photonics, Munich, Germany; maximum power of $200 \mathrm{~mW}$ ) and a diode-pumped solid-state laser with a wavelength of $532 \mathrm{~nm}$ (gem, Laser Quantum, Stockport, U.K. maximum power of $500 \mathrm{~mW}$ ) were used for excitation of Alexa Fluor 647 and Alexa Fluor 532 respectively. Laser beams were cleaned-up by bandpass filters (Semrock, NY, USA) and combined by appropriate dichroic mirrors (LaserMUX filters, Semrock). Afterwards they were focused onto the back focal plane of the high numerical oil-immersion objective (alpha Plan-Apochromat 100x/1.46 Oil DIC), which is part of an inverted fluorescence microscope (Zeiss Axio Observer.Z1, Carl Zeiss Microscopy) equipped with an autofocus system (Definite Focus, Carl Zeiss Microscopy). To separate the excitation light from the fluorescence light, a suitable dichroic beam splitter (Semrock) was placed into the light path before the laser beams enter the objective. Fluorescence light of Alexa
Fluor 647 and Alexa Fluor 532 was collected by the objective and splitted by a dichroic mirror (Chroma, Bellows Falls, Vermont, USA) to two separate EMCCD cameras (iXon Ultra 897, Andor Technology, Belfast, U.K.). Before entering the cameras, it was filtered by appropriate detection filters (Semrock/Chroma). For every image, $15 \times 10^{3}$ frames were taken with an integration time of $10 \mathrm{~ms}$ per frame. Data analysis was performed using ThunderSTORM (Ovesny et al. 2014). Gold beads were used for drift correction.

\section{Electrophysiological recordings}

Single-cell patch-clamp recordings were performed to investigate functional maturation of hiPSC-derived 5-HT specific neurons. Cultured neurons were collected from 24-well culture plates and whole-cell recordings of at least 10 neurons per independent experiment $(n=3)$ were performed weekly over a period of 6 weeks at room temperature in a bath solution consisting of $135 \mathrm{mM} \mathrm{NaCl}, 5.4 \mathrm{mM}$ $\mathrm{KCl}, 1.8 \mathrm{mM} \mathrm{CaCl}_{2}, 1 \mathrm{mM} \mathrm{MgCl} 2,10 \mathrm{mM}$ glucose, $5 \mathrm{mM}$ HEPES, pH 7.4 as previously reported (Hamill et al. 1981). Patch pipettes were pulled from borosilicate glass capillaries (DWK Life Sciences, Wertheim, Germany) and heatpolished to give input resistances of 2-5 M $\Omega$ (whole-cell). The pipette recording solution contained $120 \mathrm{mM}$ potassium methansulfonate $\left(\mathrm{CH}_{3} \mathrm{KO}_{3} \mathrm{~S}\right), 4 \mathrm{mM} \mathrm{NaCl}, 1 \mathrm{mM} \mathrm{MgCl}{ }_{2}$, $0.5 \mathrm{mM} \mathrm{CaCl} 2,10 \mathrm{mM}$ ethylene-bis(oxyethylenenitrilo) tetraacetate (EGTA), $3 \mathrm{mM}$ ATP-Mg, $0.3 \mathrm{mM}$ GTP-TRIS, and $10 \mathrm{mM}$ HEPES (pH 7.2). Currents were recorded with an EPC9 (HEKA, Lambrecht/Pfalz, Germany) patch-clamp amplifier and low pass-filtered at $2 \mathrm{kHz}$. Stimulation and data acquisition were controlled by the PULSE/PULSEFIT software package (HEKA) on a Macintosh computer, and data analysis was performed with IGOR software (WaveMetrics, Lake Oswego, OR, USA). Properties of 5-HT specific neurons were analyzed according to existing electrophysiological criteria (de Kock et al. 2006; Li et al. 2001; Vandermaelen and Aghajanian 1983), such as amplitude, halfheight width (HHW) and action potential frequency. Our main criteria for 5-HT specific neuron identity were action potential HHW of $>1.5 \mathrm{~ms}$ and maximal sustained firing rate of $<12 \mathrm{~Hz}$ (Mlinar et al. 2015).

\section{Statistical analyses}

Except of qPCR analysis $(n=2)$, all experiments described in this study have been conducted in a total of three independent differentiations $(n=3)$. Values were expressed as mean \pm s.e.m. Differences between means were assessed by one-way analysis of variance (ANOVA) and $P<0.05$ was considered as significant. 
A

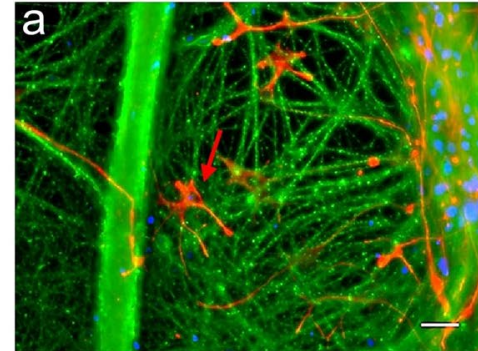

BTubIII/GFAP/DAPI

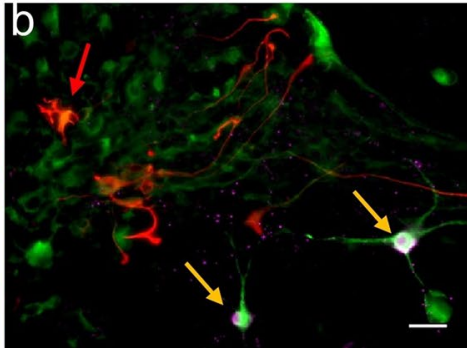

MAP2/GFAP/NeuN

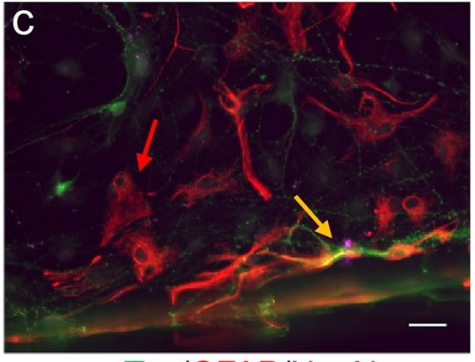

Tau/GFAP/NeuN

B
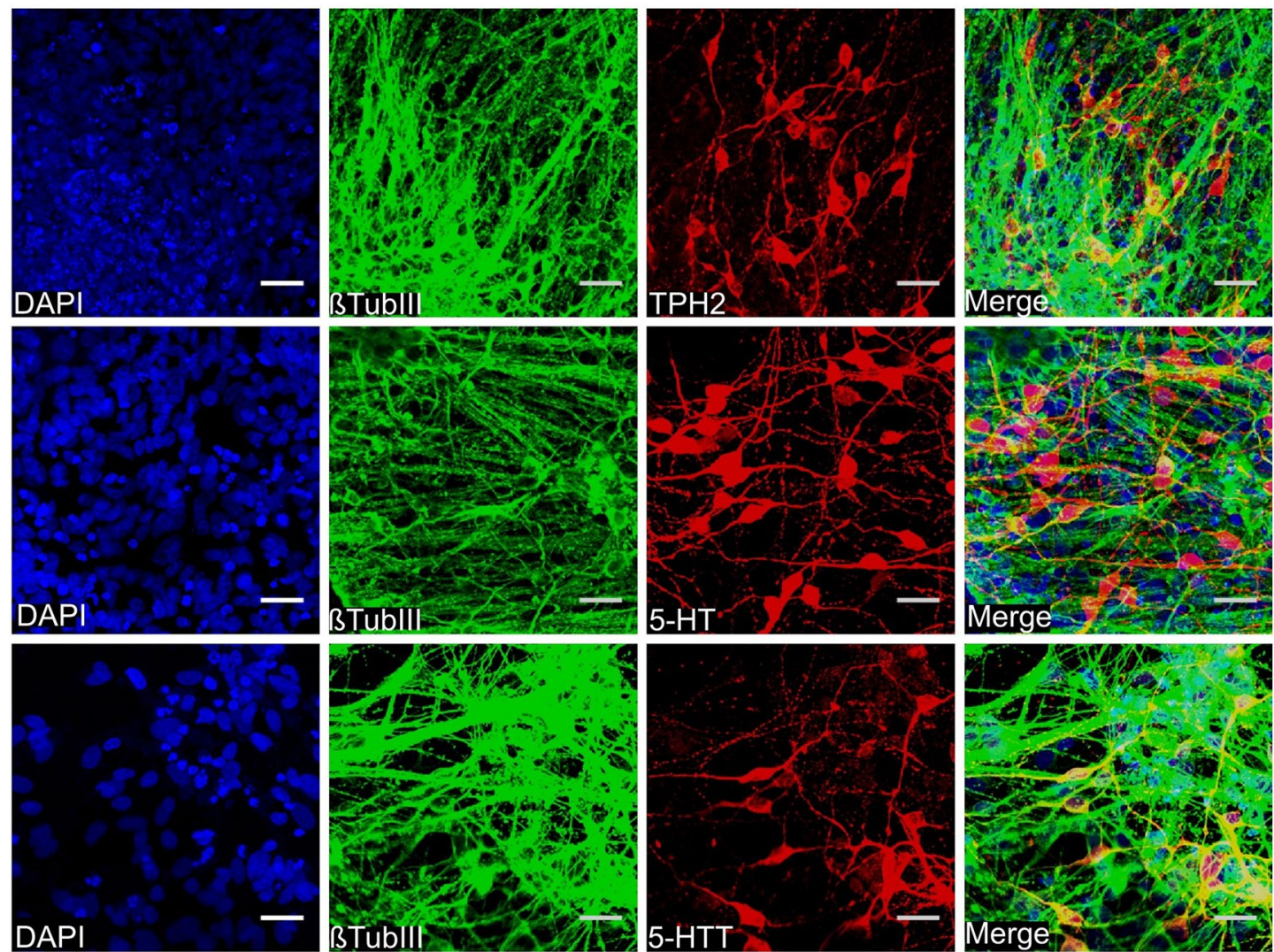

Fig. 2 Generation of 5-HT specific neurons from human iPSCderived 5-HT specific progenitors. A Our differentiation protocol generates $\beta$ TUBIII + neurons (A, a stained in green) and GFAP + astrocytes (A, a-c, stained in red, examples marked by red arrows) following 5 weeks of neuronal maturation. 5-week-old neurons were additionally proven to be mature neurons illustrated by positive staining of $(\mathbf{A}, \mathbf{b}) \mathrm{MAP} 2$ (stained in green) and NeuN (stained in magenta) and $(\mathbf{A}, \mathbf{c})$ Tau (stained in green), and NeuN (stained in magenta). Mature neurons are marked by yellow arrows. Pictures were taken using epifluorescence microscopy. B All neurons were costained for an antibody against $\beta$ TUBIII and TPH2, 5-HT, and 5-HTT after 4-5 weeks of neuronal maturation (differentiation week 7-8). Pictures were taken using confocal microscopy. Scale bar: $50 \mu \mathrm{m}$. Cell nuclei were counterstained with DAPI and Alexa Fluor 488 ( $\beta$ TUBIII, MAP2, Tau) and Alexa Fluor 555 (GFAP, TPH2, 5-HT, 5-HTT) and Alexa Fluor 647 (NeuN) were used to visualize target proteins. 5-HT specific neuronal differentiation was verified using the JMUi001-A iPS line (data not shown) 


\section{Results}

\section{Hindbrain progenitors differentiate into a mixed culture of specific neuronal subtypes}

After 5 weeks of neuronal maturation, most of the cells developed into $\beta$ TUBIII + neurons $(>70 \%)$ and only a very low percentage of glial fibrillary acidic protein positive (GFAP +) astrocytes (Fig. 2A, a). Additionally, these 5 -week-old neurons were proven to already be mature by positive staining of dendritic marker microtubule-associated protein 2 (MAP2), axonal marker Tau protein and neuronal nuclear protein (NeuN) (Fig. 2a, b, c). Among the $\beta$ TUBIII + cells around $42 \%$ of the neurons in our culture system displayed a serotonergic phenotype illustrated by a positive TPH $2(\mathrm{TPH} 2+)$ staining. To determine specific neuronal subtypes in our neuronal cell culture system we performed IF of neuronal subtype markers (Fig. 3a) and counting analyses (Fig. 3c). These investigations revealed that in addition to the $42 \%$ of 5 -HT specific neurons, $40 \%$

a
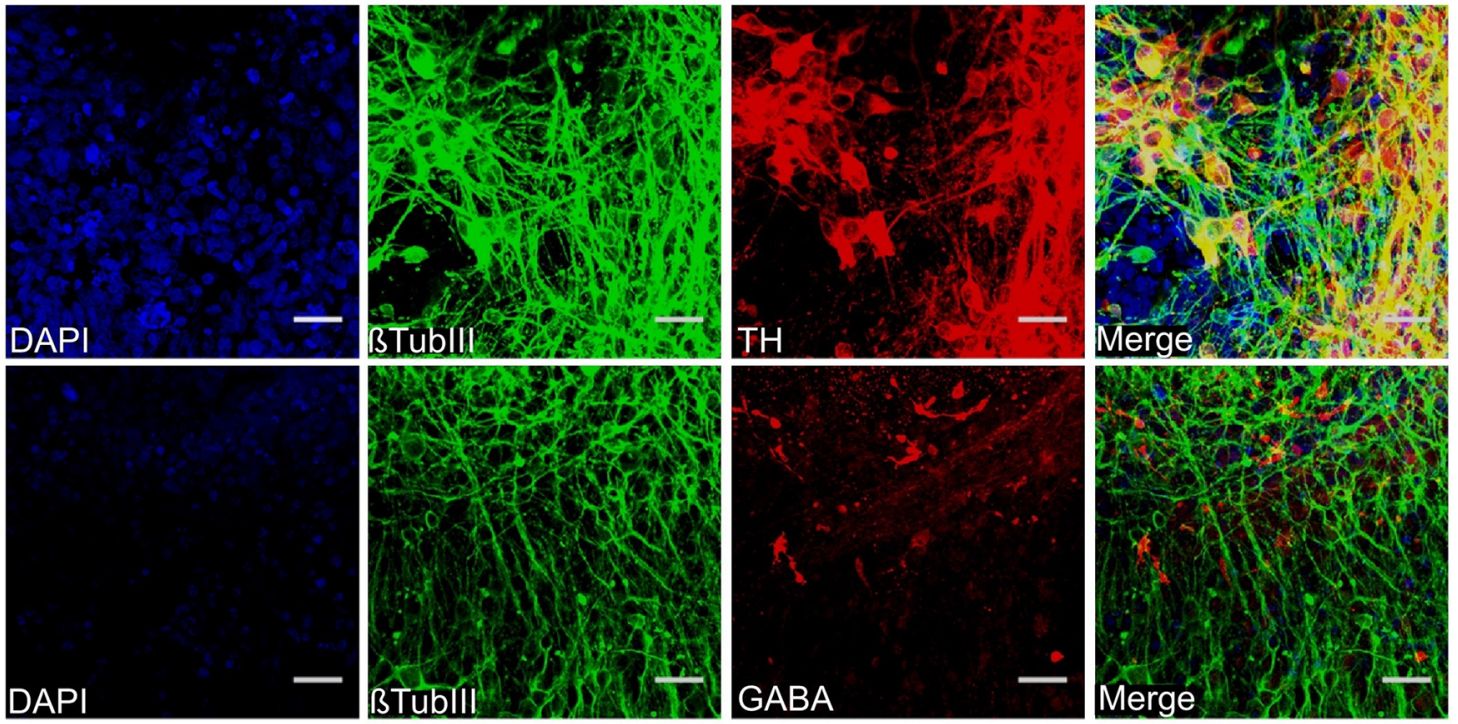

b

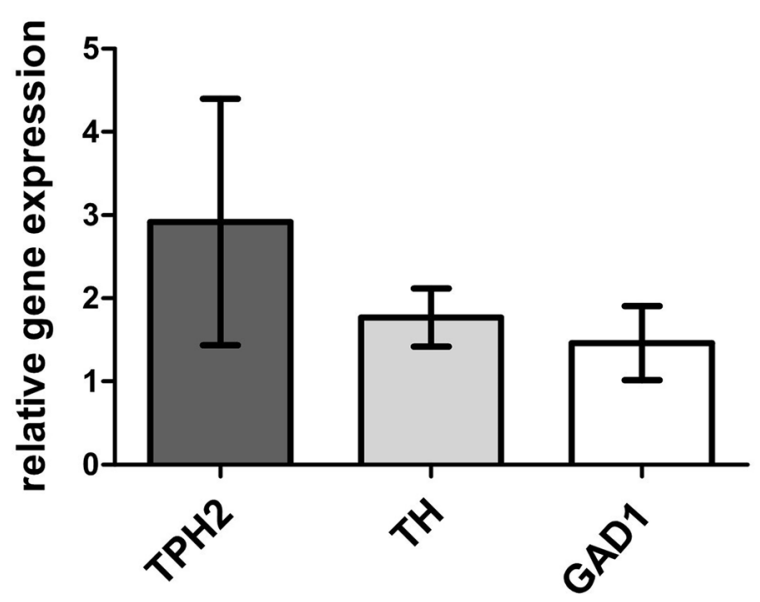

C

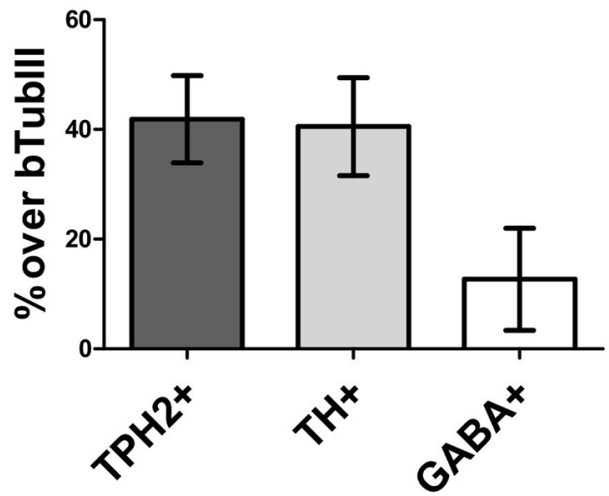

Fig. 3 Specification of different neuronal subtypes. a Neurons were co-stained for an antibody against $\beta$ TUBIII, TH, and GABA after 4-5 weeks of neuronal maturation (differentiation week 7-8). Pictures were taken using confocal microscopy. Scale bar: $50 \mu \mathrm{m}$. Cell nuclei were counterstained with DAPI and Alexa Fluor 488 ( $\beta$ TUBIII) and Alexa Fluor 555 (TH, GABA) were used to visual-

ize target proteins. b Relative gene expression levels of the human iPSC-derived 5-HT specific ( $\mathrm{TPH} 2+)$, catecholaminergic $(\mathrm{TH}+)$ and GABAergic (GAD1 + ) neurons ( $n=2$ independent differentiations). $\mathbf{c}$ Quantification of the amount of 5-HT specific (TPH2 +$)$, catecholaminergic $(\mathrm{TH}+)$ and GABAergic $(\mathrm{GABA}+)$ neurons within the neuronal cell culture system ( $n=3$ independent differentiations) 
of all the neurons showed a catecholaminergic and $12 \%$ a GABAergic phenotype. mRNA expression of subtype markers $T P H 2, T H$, and $G A D 1$ were shown by qRT-PCR (Fig. 3b).

\section{hiPSC-derived 5-HT specific neurons display phenotypes of both median and dorsal raphe 5-HT specific neurons}

Due to the importance of CDH13 for neurodevelopmental disorders, the expression of this protein was analyzed in hiPSC-derived 5-HT specific neurons using epifluorescence microscopy and SIM. Our findings indicated that CDH13 was expressed in a subset of the TPH2 + neurons (Figs. 4,
S2B) but was lacking from the majority of 5-HT specific neurons identified in our culture (Fig. 4b). Among Nestin + / HOXA $2+$ NPCs the proportion of CDH13 + cells was only $1.5 \%$. These CDH13 + NPCs build small cell clusters which occur only sparsely (Fig. S2A). However, after 8 weeks of neuronal maturation CDH13 immunoreactivity was evident equally across the whole culture with about $40 \%$ of BTUBIII + /CDH13 + cells being also CDH13-positive (Fig. $\mathrm{S} 2 \mathrm{~B})$. We observed the same expression pattern previously detected in murine 5-HT specific neurons, with CDH13 outlining both the soma and extending neurites (Fig. 4a, c, d). A three-dimensional reconstruction of these $\mathrm{CDH} 13+5-\mathrm{HT}$ specific neurons suggested a potential role in cell-cell interaction, showing two TPH 2 + neurons in close proximity with
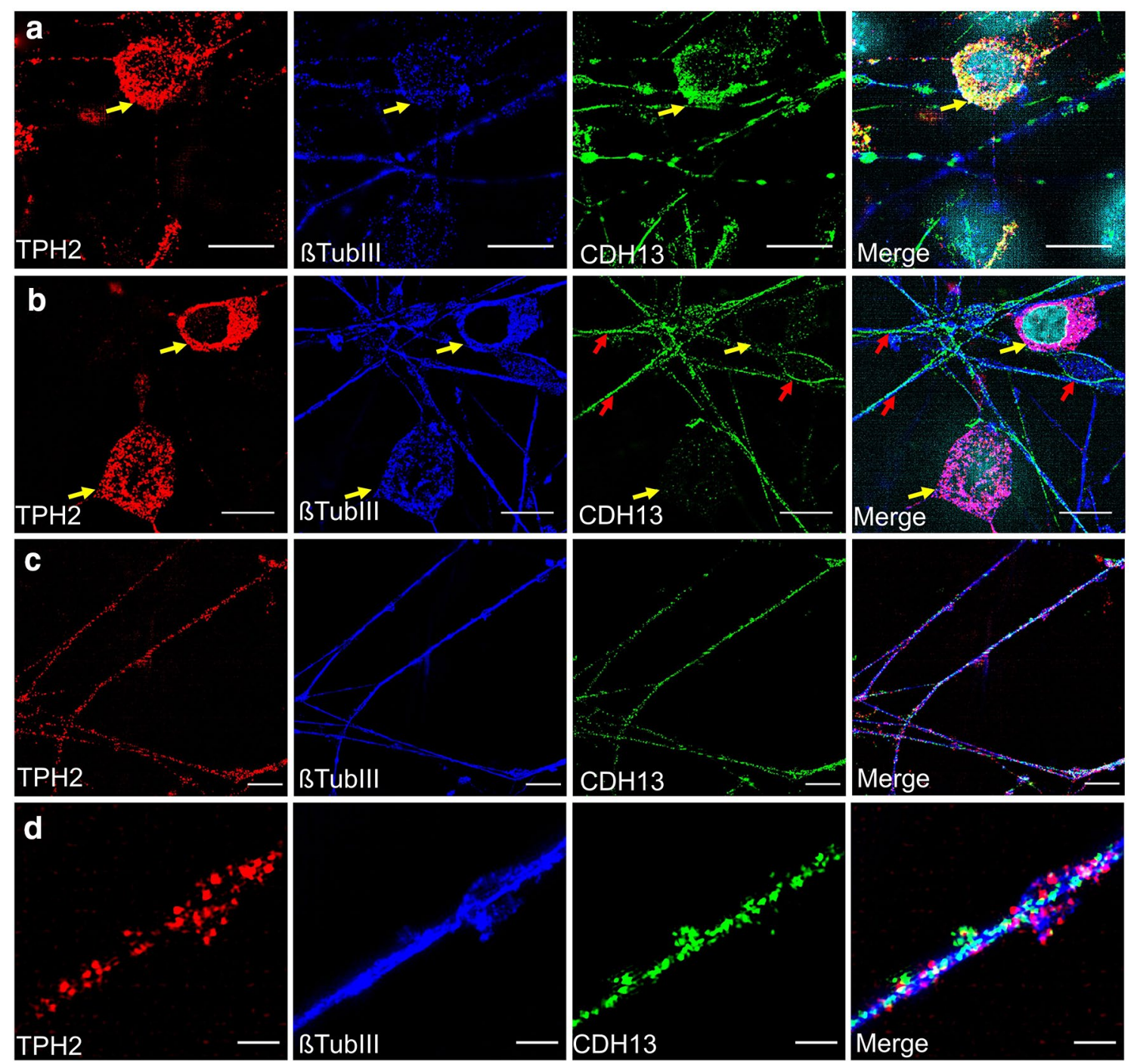

Fig. 4 CDH13 expression in TPH2 + neurons using SIM. a IF staining of a TPH2 + neuron which is positive for $\mathrm{CDH} 13$ (yellow arrows). b IF staining of TPH2 + neurons which are negative for CDH13 (yellow arrows). Additionally, $\beta$ TUBIII + fibers that are negative for TPH 2 are immunoreactive for $\mathrm{CDH} 13$ and marked by a red arrow. c IF staining of TPH2 + fibers being positive for CDH13. d Closeup image of (c). Scale bar: a, b, c $10 \mu \mathrm{m}$; d $2 \mu \mathrm{m}$. Alexa Fluor 488 ( $\beta$ TUBIII), Alexa Fluor 555 (TPH2) and Alexa Fluor 647 (CDH13) were used to visualize target proteins 
CDH13 expression at the contact region between them (Supplementary video 1 ).

\section{Electrophysiological signature of hiPSC-derived 5-HT specific neurons}

Voltage steps from -100 to $+70 \mathrm{mV}$ generated inward $\mathrm{Na}^{+}$and outward $\mathrm{K}^{+}$currents (Fig. 5a), responsible for the induction of action potentials. Current injections from -120 to $+120 \mathrm{pA}$ elicited action potentials (Fig. 5b). Generated neurons displayed typical 5-HT specific neuron identity proven by action potential HHW of $>1.5 \mathrm{~ms}$ (Fig. 5c) and maximal sustained firing rate of $<12 \mathrm{~Hz}$ (Fig. 5d, h). During the first 4 weeks of maturation the amplitude of the action potentials increased significantly (Fig. 5e: amplitude: $w 1$ : $61.52 \pm 5.57 \mathrm{mV}, n=14$; w2: $67.18 \pm 5.42 \mathrm{mV}, n=16$; w3: $80.67 \pm 3.98 \mathrm{mV}, n=22 ; \mathrm{w} 4: 86,56 \pm 5.41 \mathrm{mV}, n=22$; w5: $87.62 \pm 3.64 \mathrm{mV}, n=17$; w6: $87.48 \pm 3.71 \mathrm{mV}, n=5$; $\mathrm{F}(5,90)=4.538, P=0.001)$, whereas the duration of action potentials decreased (Fig. 5f: HHW: w1: $7.22 \pm 1.31 \mathrm{~ms}$, $n=14$; w2: $7.02 \pm 1.24 \mathrm{~ms}, n=16$; w3: $4.13 \pm 1.01 \mathrm{~ms}$, $n=22$; w4: $3.09 \pm 0.3 \mathrm{~ms}, n=22$; w5: $2.83 \pm 0.57 \mathrm{~ms}$, $n=17$; w6: $2.52 \pm 0.34 \mathrm{~ms}, n=5 ; \mathrm{F}(5,90)=4.453$, $P=0.0011)$. The membrane potential of the neurons did not change significantly over time (Fig. 5g: Vm: w1:
$-48.75 \pm 1.98 \mathrm{mV}, n=14 ; \mathrm{w} 2:-50 \pm 1.14 \mathrm{mV}, n=16 ; \mathrm{w} 3:$ $-54.85 \pm 2.37 \mathrm{mV}, n=22 ; \mathrm{w} 4:-54.29 \pm 1.28 \mathrm{mV}, n=22$; w5: $-53.88 \pm 1.52 \mathrm{mV}, n=17$; w6: $-53.9 \pm 1.94 \mathrm{mV}$, $n=5 ; \mathrm{F}(5,90)=1.592, P=0.1705)$ as well as the spike frequency (Fig. 5h: frequency: w1: $1.92 \pm 1.74 \mathrm{~Hz}, n=4$; w2: $0.83 \pm 0.69 \mathrm{~Hz}, n=5$; w3: $0.92 \pm 0.7 \mathrm{~Hz}, n=8$; w4: $3.34 \pm 0.9 \mathrm{~Hz}, n=15$; w5: $1.83 \pm 0.52 \mathrm{~Hz}, n=12$; w6: $0.6 \pm 0.23 \mathrm{~Hz}, n=3 ; \mathrm{F}(5,41)=1.447, P=0.2283)$.

\section{Super-resolution imaging of synaptic connectivity}

To further evaluate synapse formation and connectivity among the differentiated 5-HT specific neurons, we performed confocal microscopy and $d$ STORM, a super-resolution microscopy technique to visualize the presence of synaptic structures (Fig. 6). Here, neurons immunoreactive for TPH2 were additionally analyzed for the expression of synaptic proteins. Pre-and postsynaptic structure and machinery was confirmed by imaging Bassoon, a marker for the presynaptic active zone, together with the major scaffolding protein in the excitatory postsynaptic density (PSD) PSD-95 or Homer, a PSD scaffolding protein. As shown in Fig. 6A, $\mathrm{B}$, Bassoon was not only expressed in axon terminals, but was also evenly distributed along the soma and extension of $\mathrm{TPH} 2+5-\mathrm{HT}$ specific neurons. Interestingly, these neurons a

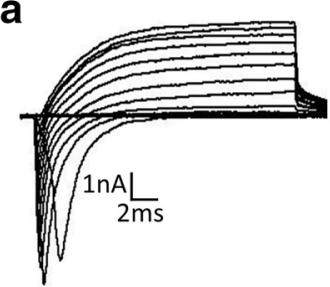

b

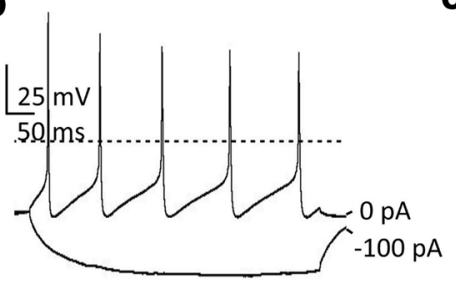

e

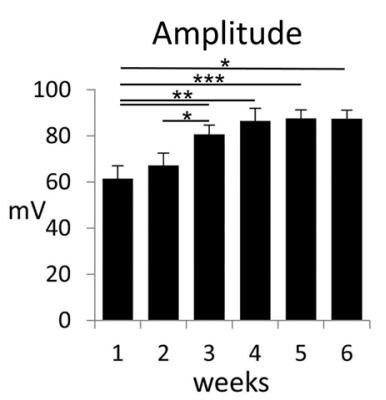

f
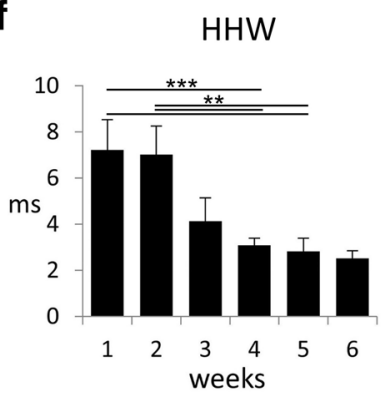

C
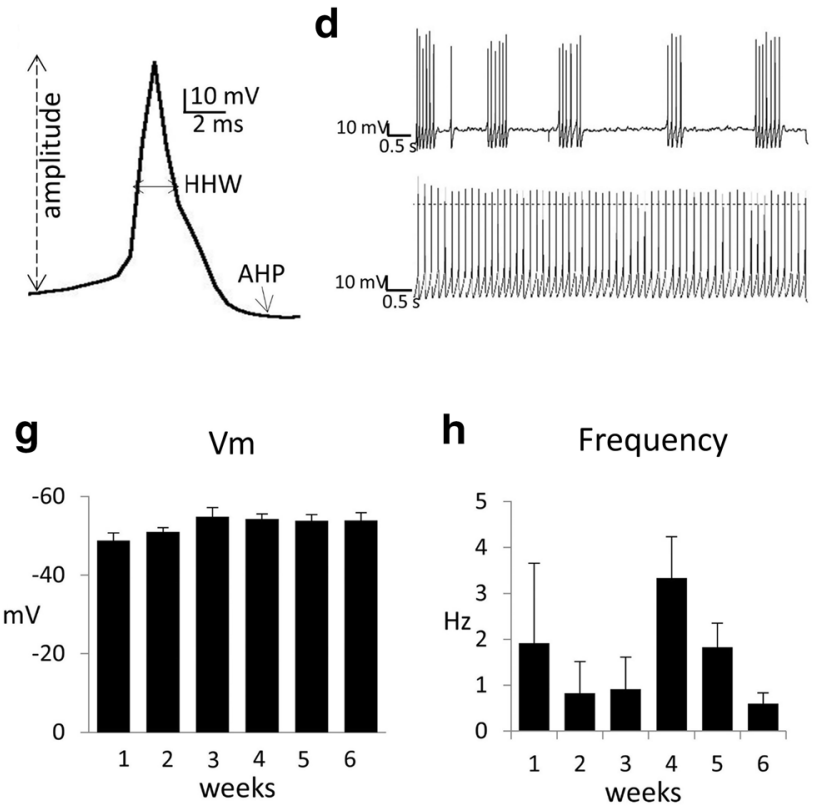

h Frequency

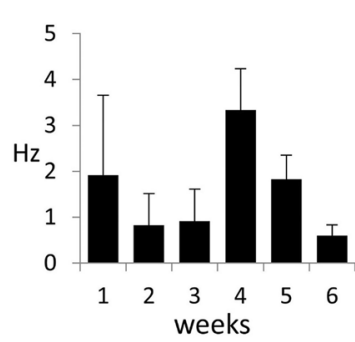

Fig. 5 Electrophysiological properties of human iPSC-derived 5-HT specific neurons. a Voltage-gated $\mathrm{Na}+$ and $\mathrm{K}+$ currents triggered by voltage steps from -100 to $+70 \mathrm{mV}$ at a holding potential of $80 \mathrm{mV}$. b Action potentials were induced upon injection of current steps from -120 to $+120 \mathrm{pA}$. Depicted are traces at $-100 \mathrm{pA}$ and at $0 \mathrm{pA}$ with spontaneous action potentials. $\mathbf{c}$ Single action potential on an expanded time scale. Indicated are amplitude, HHW and afterhyperpolarization (AHP). d Neurons display two typical modes of activ-

ity: bursts with intercalated pauses (upper trace) or activity with constant frequency (lower trace). $\mathbf{e}-\mathbf{h}$ Bar graphs of electrophysiological properties of human iPSC-derived 5-HT specific neurons over a time period of 6 weeks. e AP amplitude, f half-height width (HHW), g resting membrane potential and $\mathbf{h} \mathrm{AP}$ frequency. Electrophysiological signature characteristic of serotonergic neuron was verified using the JMUi001-A iPS line (data not shown). Pairwise post-hoc t-tests, ${ }^{*} P$ $<.05, * * P<.01, * * * P<.001$ 
Fig. 6 Human iPSC-derived 5-HT specific neurons function rather via somatodendritic 5-HT release than synaptic transmission. A The presynaptic marker Bassoon is evenly expressed along soma and extensions of TPH2 + human iPSC-derived neurons. A' Close-up image of (A). B Bassoon is localized in close proximity to the postsynaptic marker PSD-95 in dendrites and cell bodies of TPH2 + neurons. C $d$ STORM revealed a higher expression of Bassoon compared to the postsynaptic marker Homer in TPH2 + neurons. C' Close-up images of (C). C"' Example images illustrating contact points between Homer and Bassoon. Simplified schematic illustrations of Bassoon, PSD95 and Homer expression in (D) volume transmission and (E) synaptic transmission. Scale bar: A $30 \mu \mathrm{m} ; \mathbf{A}^{\prime} 10 \mu \mathrm{m} ; \mathbf{B}$ $10 \mu \mathrm{m} ; \mathbf{C} 2 \mu \mathrm{m} ; \mathbf{C}^{\prime} 1 \mu \mathrm{m}$ and C" $150 \mathrm{~nm}$. Alexa Fluor 488 (PSD-95; MAP2), Alexa Fluor 532 (Homer; TPH2) and Alexa Fluor 647 (Bassoon) were used to visualize target proteins
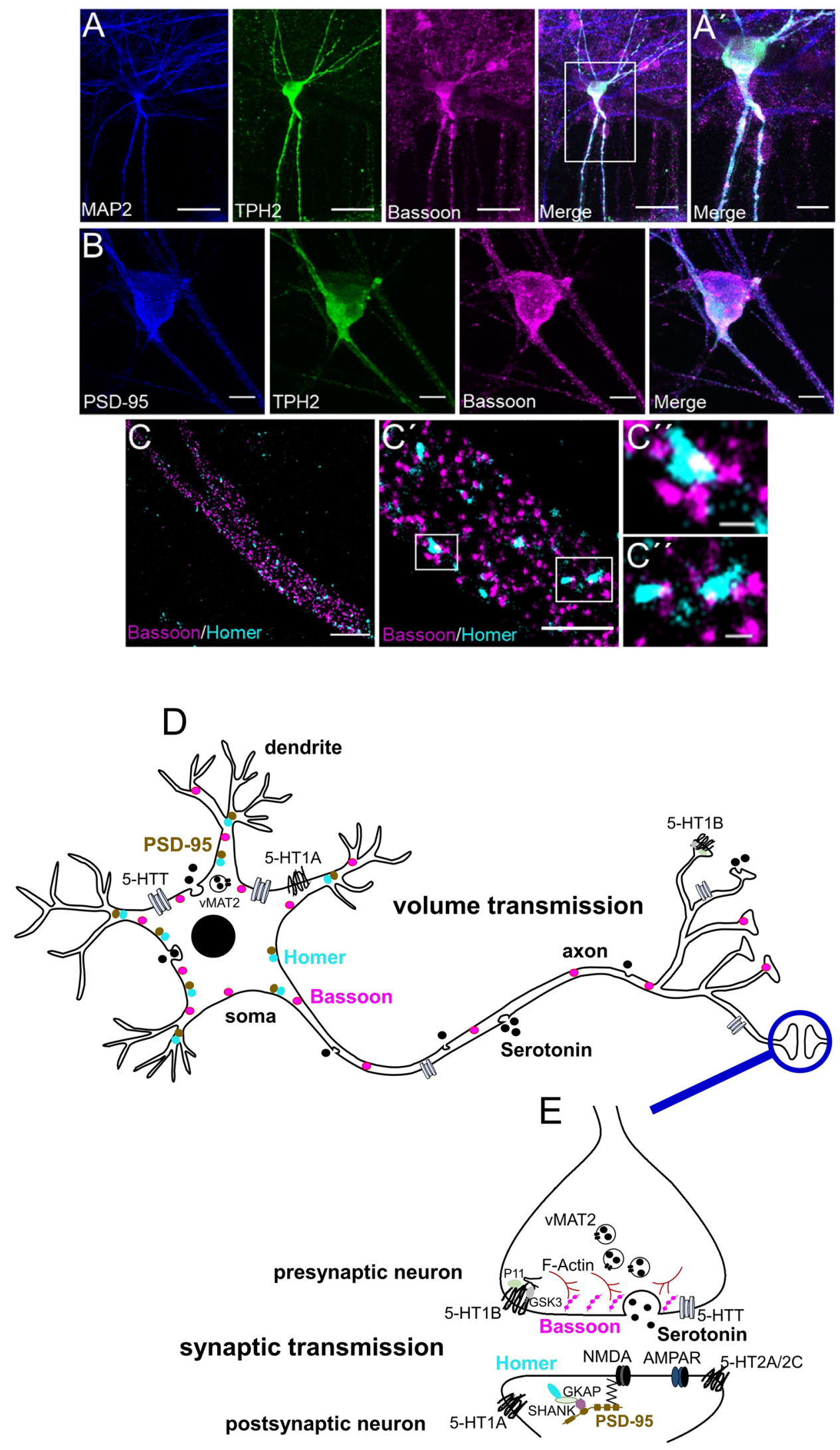
showed Bassoon expression in Map2 + dendrites (Fig. 6A) and in close proximity to PSD-95 (Fig. 6B). We implemented Alexa Fluor 647 for Bassoon and Alexa Fluor 532 for the labeling of Homer as a suitable combination for the two-color $d$ STORM analysis (Fig. 6C). TPH2 + neurons were targeted for presynaptic Bassoon, as well as postsynaptic Homer, which led to the identification of an overall more pronounced expression of Bassoon compared to Homer (Fig. 6C to $\mathrm{C}^{\prime \prime}$ ). However, even when close proximity of contact points between Homer and Bassoon was observed (Fig. 6C"), no typical bar structures illustrating synaptic transmission were identified. Generated 5-HT specific neurons thus appear more likely to function via somatodendritic 5-HT release (Fig. 6D) rather than via synaptic transmission (Fig. 6E).

\section{Discussion}

This study reports the generation 5-HT specific neurons from hiPSCs. In addition to a high percentage of 5-HT specific neurons $(\sim 42 \%)$, also catecholaminergic $(\sim 40 \%)$ and GABAergic neurons $(\sim 12 \%)$ were generated. Immunohistochemistry confirmed neuronal subtype-specific marker expression, while high-end fluorescence microscopy and whole-cell patch clamp recordings illustrated the synaptic compartment of human 5-HT specific neurons and revealed characteristic electrophysiological features.

In our first attempts to generate functionally active 5-HT specific neurons from hiPSCs we strictly followed the protocol published by Lu and associates which is based on an adherent culture system (Lu et al. 2016). An efficiency of more than $60 \%$ 5-HT specific neurons was reported for this approach. However, during our undertaking to replicate the differentiation efficiencies the adherent system resulted in a low percentage of neuronal cells (5-10\%). Subsequently, we adjusted the protocol to an EB formation system (Fig. 1A) as we attributed the loss of neural progenitors to repetitive splitting during the neural progenitor expansion steps. The applied small molecules and time course of their administration were maintained as in the original protocol. In our alternative EB formation approach, we opted for positive selection of cells by carefully lifting neural rosettes after 1 week of ventralization by $\mathrm{SHH}$ and selecting neural tube-like structures following one further week of 5-HT fate specification (SHH + FGF4). Thereby, we avoided splitting cells during the entire differentiation process, which resulted in a nearly pure neuronal culture. Finally, these adjustments enriched the cell population to $42 \%$ 5-HT specific neurons within the overall number of neuronal cells. Recently, a similar adaptation of the original protocol (Lu et al. 2016) likewise with implementation of an EB formation system with efficiencies of more than $70 \%$ was reported (Farrelly et al. 2019; Vadodaria et al. 2019). Thus, it can be argued that initiation of serotonergic differentiation in suspension culture is a reasonable approach if adherent methods do not result in good differentiation efficiencies. This is in line with the finding that neural induction by dual SMAD inhibition (also used by our protocol with small molecules DMH1 and $\mathrm{SB}$ ) in free-floating EBs results in an even higher proliferative capacity and differentiation potential with resulting NPCs expressing higher amounts of SHH and Nestin, when compared to an adherent culture system (Pauly et al. 2018). However, the inconsistencies of an EB system with variation in size of generated aggregates may have been one reason why we continued to gain less 5-HT specific neurons compared to the previously published protocols (Farrelly et al. 2019; Lu et al. 2016; Vadodaria et al. 2019). Since it is challenging to control the development of cells within these aggregates, EBs are known to display a complex differentiation system. A wide range of EB sizes and geometries is likely as EB cultures favor further aggregation (Dang et al. 2002). Therefore, we only picked medium-sized round EBs (200-300 $\mu \mathrm{m}$ in diameter) and plated them on PO/laminincoated plates to allow rosette formation. Another reason why we gained a lower proportion of 5-HT specific cells than similar EB-based protocols (Farrelly et al. 2019; Vadodaria et al. 2019) might be that we seeded NPCs directly after the 3-week differentiation period, whereas the former suggest propagating NPCs for some passages at high density under adherent conditions which might stabilize the cells' serotonergic profile.

The apparent shortcoming of a comparatively (Farrelly et al. 2019; Lu et al. 2016; Vadodaria et al. 2019) less pure serotonergic culture with our protocol might be outweighed by the advantage of a mixed neuronal culture system facilitating the investigation of interactions between different neuronal subtypes. Overall, we achieved a balanced neuronal culture of 5-HT specific ( 42\%) and catecholaminergic ( $40 \%)$ neurons. Of note, the interaction of 5-HT specific neurons with catecholaminergic (dopaminergic and noradrenergic) neurons is of relevance for the pathogenesis of neurodevelopmental conditions (Garcia et al. 2019; Kapur and Remington 1996; Oades 2008) and has been examined in several animal-based studies (Daw et al. 2002; Wong et al. 1995). Thus, our differentiation protocol creates a model system that may be practical to further study the interaction of human 5-HT specific and catecholaminergic neurons (for review, Di Giovanni et al. 2010; Monti and Jantos 2008; Niederkofler et al. 2015). The identification of different neuronal subpopulations is in line with previous findings of catecholaminergic and GABAergic neurons among 5-HT specific neurons obtained by the differentiation method under investigation ( $\mathrm{Lu}$ et al. 2016).

The original protocol generated a culture of high-density median raphe 5-HT specific neurons (Lu et al. 2016). 
Converging evidence, however, suggests differences between median and dorsal raphe 5-HT specific neurons with respect to their electrophysiological properties (Beck et al. 2004) and functional connectivity (Beliveau et al. 2015). Moreover, dorsal and median raphe nuclei have been ascribed differential roles for pro-social, aggressive (Balazsfi et al. 2018), and addictive behavior (Verheij et al. 2018). Therefore, we examined our approach for subdivision into median and dorsal raphe 5-HT specific neurons. We recently demonstrated that $\mathrm{CDH} 13$ contributes to the migration of 5-HT specific neurons to distinct subregions of the raphe nuclei, preferentially the lateral wing of the dorsal raphe (Andrea Forero et al. 2017) and has been associated with various neurodevelopmental disorders including ADHD (Lasky-Su et al. 2008; Lesch et al. 2008; Neale et al. 2010) and ASD (Sanders et al. 2011, 2015). SIM microscopy of our 5-HT specific neurons indicates that $\mathrm{CDH} 13$ is highly expressed in a subset of cultured TPH2 + neurons. Whereas only $1.5 \%$ of 5-HT specific NPCs expressed CDH13, neuronal maturation led to an increase in $\mathrm{CDH} 13+5-\mathrm{HT}$ specific cells with about $40 \%$ of TPH $2+/$ BTUBIII + neurons displaying immunoreactivity for $\mathrm{CDH} 13+$ after 8 weeks of neuronal maturation. This time-dependent increase in $\mathrm{CDH} 13+$ cells between 5-HT specific neurogenesis and maturation further strengthens the view that $\mathrm{CDH} 13$ is involved in the development of the 5-HT system (Forero et al. 2020). We conclude that differentiation may generate a mixture of median and dorsal raphe 5-HT specific neurons, and we provide evidence that proteins which have been identified to influence the risk for neurodevelopmental disorders may be studied using this cell system. However, further investigation including additional markers for these various subsets of raphe nuclei in human-derived cells is necessary to eventually distinguish cells with rhombomere 1 vs. rhombomere $2 / 3$ specification which give rise to dorsal and median raphe neurons, respectively (Alonso et al. 2013; Bang et al. 2012; Jensen et al. 2008).

To analyze neuronal maturity we stained for markers of neuronal maturation, such as the dendritic marker MAP2, the axonal marker Tau, and NeuN, a marker labeling maturing neurons. Interestingly, already after 5 weeks of neuronal maturation generated neurons were expressing these markers. Thus, our differentiation protocol enables a rapid and efficient generation of fully mature neurons and also yields a distinct proportion of astrocytes that are known to support neuron function. Therefore, the astrocytes possibly benefit those generated neurons in vitro and accelerate maturation. However, to further prove reliable differentiation of hiPSCs into 5-HT specific neurons that form synaptic connections and show the characteristic features of functional in vivo 5-HT specific neurons, we examined our cells using electrophysiological techniques as well as $d$ STORM.
To assess functional maturation of 5-HT specific neurons, whole-cell recordings were performed weekly over a period of 6 weeks. These measurements revealed typical ion currents, repetitive firing elicited by current injections and spontaneous firing in neurons detectable already after 1 week of neuronal maturation. Interestingly, the rate of maturation and firing properties were similar within experiments and over time. Using electrophysiological properties for identifying neurons as 5-HT specific was previously discussed (Vandermaelen and Aghajanian 1983). Some of the applied criteria, such as input resistance or afterhyperpolarisation lead to high error rates in identifying 5-HT specific neurons as was demonstrated by Calizo and colleagues (Calizo et al. 2011). The lowest error rates were shown for action potential duration. In this study, the frequency of measured action potentials varied over time, but always matched the criteria for 5-HT neuron specification and was less than $12 \mathrm{~Hz}$. Over the whole time period measured spontaneous action potential firing was evident. During the 6-week course, action potentials rose and got faster as the amplitude increased and the HHW decreased. After 4 weeks of maturation no further changes of the neurons' electrophysiological properties occurred. The frequency of action potentials remained between 0.5 and $4 \mathrm{~Hz}$, consistently meeting criteria of 5-HT specific neurons, in line with the findings of $\mathrm{Lu}$ and associates ( $\mathrm{Lu}$ et al. 2016) who described an average firing frequency of $2.9 \mathrm{~Hz}$. Our longitudinal electrophysiological data indicate that functional maturation of hiPSC-derived 5-HT specific neurons requires at least 4 weeks of outgrowth in NMM. Of note, we found two modes of firing activity: regular clock-like tonic activity with constant frequency and burst-firing activity. It is discussed that the regular firing pattern is associated with a constant basal tonic 5-HT release by somatodendritic volume transmission, whereas burst firing leads to phasic synaptic neurotransmission (Gartside et al. 2000; Quentin et al. 2018). Hence, our electrophysiological findings are a first indicator that these two modes of neurotransmission might also occur in hiPSC-derived 5-HT specific neurons. HHW and frequency of action potentials are sensitive indicators for 5-HT specific neurons, but cell types might not be distinguished by their electrophysiological signatures alone.

Therefore, we additionally confirmed synaptic connectivity among differentiated 5-HT specific neurons using confocal microscopy and the super-resolution microscopy technique $d$ STORM which allows to precisely visualize the existence of synaptic structures (Heilemann et al. 2008, van de Linde et al. 2011). 8-week-old TPH 2 + neurons express Bassoon, a marker for the presynaptic active zone, as well as PSD-95 and Homer, the postsynaptic density scaffolding protein (Bresler et al. 2004; Dresbach et al. 2006; Tao-Cheng et al. 2014). Bassoon as a marker for the active zone was, therefore, used to identify where 
hiPSC-derived 5-HT specific neurons form synapses with the property to organize neurotransmitter release. However, we observed that Bassoon is not exclusively restricted to axon terminals as seen in hippocampal neurons, but is evenly distributed throughout the cell, and that there is a lack of coinciding pre-and postsynaptic bar structures. This supports the assumption that our in vitro 5-HT specific neurons communicate through non-synaptic axonal and somatodendritic release, in addition to synaptic transmission (Adell et al. 2002; De-Miguel and Trueta 2005; Lau et al. 2010; Vizi et al. 2004).

The results of our study indicate that an EB formation system can be alternatively used if an adherent protocol does not result in reliable ventral hindbrain induction for the generation of 5-HT specific neurons from hiPSCs. As a limitation, it has to be noted that our study included only two hiPSC lines. Therefore, an EB-based serotonergic differentiation method might not be a better option than the adherent protocol in all cell lines. Hence, we suggest researchers to test both approaches to find the individually best fitting solution which might not only rely on characteristics of different cell lines but also on inter-lab variability and personal handling. Our approach generates mature and electrophysiologically active median and dorsal 5-HT specific neurons, side-by-side with catecholaminergic and a smaller portion of GABAergic neurons. The distribution of synaptic proteins alongside the neurons' soma and their axonal and neuritic extensions corroborates the importance of extrasynaptic "volume" transmission in the human 5-HT system. Additionally, our data substantiate the relevance of $\mathrm{CDH} 13$ for the 5-HT system. The described cell culture model is, therefore, a practical tool to specifically study the development of human 5-HT specific neurons and their interplay with other neuronal subtypes. Especially the investigation of NPC subtype markers alongside identified but not yet functionally studied potential risk genes emerging from GWAS findings, is a promising approach for further expediting the molecular underpinnings of neuropsychiatric disorders. The replication and refinement of protocols for the differentiation of neurons from hiPSCs, however, will remain a critical and fundamental challenge for the valid production of patientderived cellular models of neurodevelopmental diseases and underlying genetic mechanisms.

Supplementary Information The online version contains supplementary material available at https://doi.org/10.1007/s00702-021-02303-5.

Acknowledgements This work was supported by ERA-Net NEURON/RESPOND, No. 01EW1602B, ERA-Net NEURON/DECODE, No. FKZ01EW1902, the European Union's Seventh Framework Programme under Grant No. 602805 (Aggressotype), the Horizon 2020 Research and Innovation Programme under Grant No. 728018 (Eat2beNICE), the 5-100 Russian Academic Excellence Project, the
German Research Foundation (DFG: CRU 125, CRC TRR 58 A1/ A5, No. 44541416, and Project No. 413657723 Clinician ScientistProgramme UNION CVD) and the University of Wuerzburg in the funding programme Open Access Publishing. We also would like to thank Julia Merk for her excellent technical support.

Funding Open Access funding enabled and organized by Projekt DEAL.

Open Access This article is licensed under a Creative Commons Attribution 4.0 International License, which permits use, sharing, adaptation, distribution and reproduction in any medium or format, as long as you give appropriate credit to the original author(s) and the source, provide a link to the Creative Commons licence, and indicate if changes were made. The images or other third party material in this article are included in the article's Creative Commons licence, unless indicated otherwise in a credit line to the material. If material is not included in the article's Creative Commons licence and your intended use is not permitted by statutory regulation or exceeds the permitted use, you will need to obtain permission directly from the copyright holder. To view a copy of this licence, visit http://creativecommons.org/licenses/by/4.0/.

\section{References}

Adell A, Celada P, Abellan MT, Artigas F (2002) Origin and functional role of the extracellular serotonin in the midbrain raphe nuclei. Brain Res Brain Res Rev 39(2-3):154-180

Alonso A, Merchan P, Sandoval JE, Sanchez-Arrones L, GarciaCazorla A, Artuch R, Ferran JL, Martinez-de-la-Torre M, Puelles L (2013) Development of the serotonergic cells in murine raphe nuclei and their relations with rhombomeric domains. Brain Struct Funct 218(5):1229-1277. https://doi.org/10.1007/s0042 9-012-0456-8

Ardhanareeswaran K, Mariani J, Coppola G, Abyzov A, Vaccarino FM (2017) Human induced pluripotent stem cells for modelling neurodevelopmental disorders. Nat Rev Neurol 13(5):265-278. https://doi.org/10.1038/nrneurol.2017.45

Ashok AH, Marques TR, Jauhar S, Nour MM, Goodwin GM, Young AH, Howes OD (2017) The dopamine hypothesis of bipolar affective disorder: the state of the art and implications for treatment. Mol Psychiatry 22(5):666-679. https://doi.org/10.1038/ $\mathrm{mp} .2017 .16$

Balazsfi D, Zelena D, Demeter K, Miskolczi C, Varga ZK, Nagyvaradi A, Nyiri G, Cserep C, Baranyi M, Sperlagh B, Haller J (2018) Differential roles of the two raphe nuclei in amiable social behavior and aggression - an optogenetic study. Front Behav Neurosci 12:163. https://doi.org/10.3389/fnbeh.2018.00163

Banasr M, Hery M, Printemps R, Daszuta A (2003) Serotonin-induced increases in adult cell proliferation and neurogenesis are mediated through different and common 5-HT receptor subtypes in the dentate gyrus and the subventricular zone. Neuropsychopharmacology 29:450. https://doi.org/10.1038/sj.npp.1300320

Bang SJ, Jensen P, Dymecki SM, Commons KG (2012) Projections and interconnections of genetically defined serotonin neurons in mice. Eur J Neurosci 35(1):85-96. https://doi.org/10.111 1/j.1460-9568.2011.07936.x

Beck SG, Pan YZ, Akanwa AC, Kirby LG (2004) Median and dorsal raphe neurons are not electrophysiologically identical. J Neurophysiol 91(2):994-1005. https://doi.org/10.1152/jn.00744.2003

Beliveau V, Svarer C, Frokjaer VG, Knudsen GM, Greve DN, Fisher PM (2015) Functional connectivity of the dorsal and median raphe nuclei at rest. Neuroimage 116:187-195. https://doi.org/10.1016/j. neuroimage.2015.04.065 
Brennand KJ, Simone A, Jou J, Gelboin-Burkhart C, Tran N, Sangar S, Li Y, Mu Y, Chen G, Yu D, McCarthy S, Sebat J, Gage FH (2011) Modelling schizophrenia using human induced pluripotent stem cells. Nature 473(7346):221-225. https://doi.org/10.1038/ nature09915

Brennand KJ, Simone A, Tran N, Gage FH (2012) Modeling psychiatric disorders at the cellular and network levels. Mol Psychiatry 17:1239. https://doi.org/10.1038/mp.2012.20

Bresler T, Shapira M, Boeckers T, Dresbach T, Futter M, Garner CC, Rosenblum K, Gundelfinger ED, Ziv NE (2004) Postsynaptic density assembly is fundamentally different from presynaptic active zone assembly. J Neurosci 24(6):1507-1520. https://doi. org/10.1523/jneurosci.3819-03.2004

Calizo LH, Akanwa A, Ma X, Pan YZ, Lemos JC, Craige C, Heemstra LA, Beck SG (2011) Raphe serotonin neurons are not homogenous: electrophysiological, morphological and neurochemical evidence. Neuropharmacology 61(3):524-543. https://doi. org/10.1016/j.neuropharm.2011.04.008

Cao SY, Hu Y, Chen C, Yuan F, Xu M, Li Q, Fang KH, Chen Y, Liu Y (2017) Enhanced derivation of human pluripotent stem cellderived cortical glutamatergic neurons by a small molecule. Sci Rep 7(1):3282. https://doi.org/10.1038/s41598-017-03519-w

Dang SM, Kyba M, Perlingeiro R, Daley GQ, Zandstra PW (2002) Efficiency of embryoid body formation and hematopoietic development from embryonic stem cells in different culture systems. Biotechnol Bioeng 78(4):442-453

Daubert EA, Condron BG (2010) Serotonin: a regulator of neuronal morphology and circuitry. Trends Neurosci 33(9):424-434. https://doi.org/10.1016/j.tins.2010.05.005

Daw ND, Kakade S, Dayan P (2002) Opponent interactions between serotonin and dopamine. Neural Netw 15(4-6):603-616. https ://doi.org/10.1016/s0893-6080(02)00052-7

de Kock CP, Cornelisse LN, Burnashev N, Lodder JC, Timmerman AJ, Couey JJ, Mansvelder HD, Brussaard AB (2006) NMDA receptors trigger neurosecretion of 5-HT within dorsal raphe nucleus of the rat in the absence of action potential firing. $J$ Physiol 577(Pt 3):891-905. https://doi.org/10.1113/jphys iol.2006.115311

De-Miguel FF, Trueta C (2005) Synaptic and extrasynaptic secretion of serotonin. Cell Mol Neurobiol 25(2):297-312

Di Giovanni G, Esposito E, Di Matteo V (2010) Role of serotonin in central dopamine dysfunction. CNS Neurosci Ther 16(3):179194. https://doi.org/10.1111/j.1755-5949.2010.00135.x

Dresbach T, Torres V, Wittenmayer N, Altrock WD, Zamorano P, Zuschratter W, Nawrotzki R, Ziv NE, Garner CC, Gundelfinger ED (2006) Assembly of active zone precursor vesicles: obligatory trafficking of presynaptic cytomatrix proteins Bassoon and Piccolo via a trans-Golgi compartment. J Biol Chem 281(9):60386047. https://doi.org/10.1074/jbc.M508784200

Edwards AC, Aliev F, Bierut LJ, Bucholz KK, Edenberg H, Hesselbrock V, Kramer J, Kuperman S, Nurnberger JI Jr, Schuckit MA, Porjesz B, Dick DM (2012) Genome-wide association study of comorbid depressive syndrome and alcohol dependence. Psychiatr Genet 22(1):31-41. https://doi.org/10.1097/YPG.0b013 e32834acd07

Erzurumlu RS, Gaspar P (2012) Development and critical period plasticity of the barrel cortex. Eur J Neurosci 35(10):1540-1553. https ://doi.org/10.1111/j.1460-9568.2012.08075.x

Farrelly LA, Thompson RE, Zhao S, Lepack AE, Lyu Y, Bhanu NV, Zhang B, Loh YE, Ramakrishnan A, Vadodaria KC, Heard KJ, Erikson G, Nakadai T, Bastle RM, Lukasak BJ, Zebroski H 3rd, Alenina N, Bader M, Berton O, Roeder RG, Molina H, Gage FH, Shen L, Garcia BA, Li H, Muir TW, Maze I (2019) Histone serotonylation is a permissive modification that enhances TFIID binding to H3K4me3. Nature 567(7749):535-539. https://doi. org/10.1038/s41586-019-1024-7
Fedele S, Collo G, Behr K, Bischofberger J, Muller S, Kunath T, Christensen K, Gundner AL, Graf M, Jagasia R, Taylor V (2017) Expansion of human midbrain floor plate progenitors from induced pluripotent stem cells increases dopaminergic neuron differentiation potential. Sci Rep 7(1):6036. https://doi.org/10.1038/ s41598-017-05633-1

Forero A, Rivero O, Wäldchen S, Ku H-P, Kiser DP, Gärtner Y, Pennington LS, Waider J, Gaspar P, Jansch C, Edenhofer F, Resink TJ, Blum R, Sauer M, Lesch K-P (2017) Cadherin-13 deficiency increases dorsal raphe 5-HT neuron density and prefrontal cortex innervation in the mouse brain. Front Cell Neurosci 11:307. https ://doi.org/10.3389/fncel.2017.00307

Forero A, Ku HP, Malpartida AB, Waldchen S, Alhama-Riba J, Kulka C, Aboagye B, Norton WHJ, Young AMJ, Ding YQ, Blum R, Sauer M, Rivero O, Lesch KP (2020) Serotonin (5-HT) neuronspecific inactivation of Cadherin-13 impacts 5-HT system formation and cognitive function. Neuropharmacology 168:108018. https://doi.org/10.1016/j.neuropharm.2020.108018

Fredette BJ, Miller J, Ranscht B (1996) Inhibition of motor axon growth by T-cadherin substrata. Development 122(10):3163-3171

Garbarino VR, Gilman TL, Daws LC, Gould GG (2019) Extreme enhancement or depletion of serotonin transporter function and serotonin availability in autism spectrum disorder. Pharmacol Res 140:85-99. https://doi.org/10.1016/j.phrs.2018.07.010

Garcia LP, Witteveen JS, Middelman A, van Hulten JA, Martens GJM, Homberg JR, Kolk SM (2019) Perturbed developmental serotonin signaling affects prefrontal catecholaminergic innervation and cortical integrity. Mol Neurobiol 56(2):1405-1420. https://doi. org/10.1007/s12035-018-1105-x

Gartside SE, Hajos-Korcsok E, Bagdy E, Harsing LG Jr, Sharp T, Hajos M (2000) Neurochemical and electrophysiological studies on the functional significance of burst firing in serotonergic neurons. Neuroscience 98(2):295-300. https://doi.org/10.1016/ s0306-4522(00)00060-9

Gaspar P, Cases O, Maroteaux L (2003) The developmental role of serotonin: news from mouse molecular genetics. Nat Rev Neurosci 4(12):1002-1012. https://doi.org/10.1038/nrn1256

Gunhanlar N, Shpak G, van der Kroeg M, Gouty-Colomer LA, Munshi ST, Lendemeijer B, Ghazvini M, Dupont C, Hoogendijk WJG, Gribnau J, de Vrij FMS, Kushner SA (2018) A simplified protocol for differentiation of electrophysiologically mature neuronal networks from human induced pluripotent stem cells. Mol Psychiatry 23(5):1336-1344. https://doi.org/10.1038/mp.2017.56

Gustafsson MG (2000) Surpassing the lateral resolution limit by a factor of two using structured illumination microscopy. J Microsc 198(Pt 2):82-87

Gutknecht L, Waider J, Kraft S, Kriegebaum C, Holtmann B, Reif A, Schmitt A, Lesch KP (2008) Deficiency of brain 5-HT synthesis but serotonergic neuron formation in Tph2 knockout mice. J Neural Transm (Vienna) 115(8):1127-1132. https://doi.org/10.1007/ s00702-008-0096-6

Halevy T, Czech C, Benvenisty N (2015) Molecular mechanisms regulating the defects in fragile $\mathrm{X}$ syndrome neurons derived from human pluripotent stem cells. Stem Cell Rep 4(1):37-46. https:// doi.org/10.1016/j.stemcr.2014.10.015

Hamill OP, Marty A, Neher E, Sakmann B, Sigworth FJ (1981) Improved patch-clamp techniques for high-resolution current recording from cells and cell-free membrane patches. Pflügers Archiv 391(2):85-100. https://doi.org/10.1007/BF00656997

Hart AB, Engelhardt BE, Wardle MC, Sokoloff G, Stephens M, de Wit H, Palmer AA (2012) Genome-wide association study of d-amphetamine response in healthy volunteers identifies putative associations, including cadherin 13 (CDH13). PLoS ONE 7(8):e42646. https://doi.org/10.1371/journal.pone.0042646

Heilemann M, van de Linde S, Schuttpelz M, Kasper R, Seefeldt B, Mukherjee A, Tinnefeld P, Sauer M (2008) 
Subdiffraction-resolution fluorescence imaging with conventional fluorescent probes. Angew Chem Int Ed Engl 47(33):6172-6176. https://doi.org/10.1002/anie.200802376

Intoh A, Koszka K, Suzuki N, Eggan K (2016) SLC52A3, A BrownVialetto-van Laere syndrome candidate gene is essential for mouse development, but dispensable for motor neuron differentiation. Hum Mol Genet 25(9):1814-1823. https://doi.org/10.1093/ $\mathrm{hmg} / \mathrm{ddw} 053$

Jansch C, Gunther K, Waider J, Ziegler GC, Forero A, Kollert S, Svirin E, Puhringer D, Kwok CK, Ullmann R, Maierhofer A, Flunkert J, Haaf T, Edenhofer F, Lesch KP (2018) Generation of a human induced pluripotent stem cell (iPSC) line from a 51-year-old female with attention-deficit/hyperactivity disorder (ADHD) carrying a duplication of SLC2A3. Stem Cell Res 28:136-140. https ://doi.org/10.1016/j.scr.2018.02.005

Jensen P, Farago AF, Awatramani RB, Scott MM, Deneris ES, Dymecki SM (2008) Redefining the serotonergic system by genetic lineage. Nat Neurosci 11(4):417-419. https://doi.org/10.1038/nn2050

Jones L, McCutcheon J, Young A, Norton W (2015) Neurochemical measurements in the zebrafish brain. Front Behav Neurosci. https ://doi.org/10.3389/fnbeh.2015.00246

Kaiser T, Feng G (2015) Modeling psychiatric disorders for developing effective treatments. Nat Med 21(9):979-988. https://doi. org/10.1038/nm.3935

Kapur S, Remington G (1996) Serotonin-dopamine interaction and its relevance to schizophrenia. Am J Psychiatry 153(4):466-476. https://doi.org/10.1176/ajp.153.4.466

Kirkeby A, Nolbrant S, Tiklova K, Heuer A, Kee N, Cardoso T, Ottosson DR, Lelos MJ, Rifes P, Dunnett SB, Grealish S, Perlmann T, Parmar M (2017) Predictive markers guide differentiation to improve graft outcome in clinical translation of hesc-based therapy for parkinson's disease. Cell Stem Cell 20(1):135-148. https ://doi.org/10.1016/j.stem.2016.09.004

Kiyasova V, Gaspar P (2011) Development of raphe serotonin neurons from specification to guidance. Eur J Neurosci 34(10):1553-1562. https://doi.org/10.1111/j.1460-9568.2011.07910.x

Kriks S, Shim JW, Piao J, Ganat YM, Wakeman DR, Xie Z, CarrilloReid L, Auyeung G, Antonacci C, Buch A, Yang L, Beal MF, Surmeier DJ, Kordower JH, Tabar V, Studer L (2011) Dopamine neurons derived from human ES cells efficiently engraft in animal models of Parkinson's disease. Nature 480(7378):547-551. https ://doi.org/10.1038/nature10648

Kwok CK, Ueda Y, Kadari A, Gunther K, Ergun S, Heron A, Schnitzler AC, Rook M, Edenhofer F (2018) Scalable stirred suspension culture for the generation of billions of human induced pluripotent stem cells using single-use bioreactors. J Tissue Eng Regen Med 12(2):e1076-e1087. https://doi.org/10.1002/term.2435

Lasky-Su J, Neale BM, Franke B, Anney RJ, Zhou K, Maller JB, Vasquez AA, Chen W, Asherson P, Buitelaar J, Banaschewski T, Ebstein R, Gill M, Miranda A, Mulas F, Oades RD, Roeyers H, Rothenberger A, Sergeant J, Sonuga-Barke E, Steinhausen HC, Taylor E, Daly M, Laird N, Lange C, Faraone SV (2008) Genomewide association scan of quantitative traits for attention deficit hyperactivity disorder identifies novel associations and confirms candidate gene associations. Am J Med Genet B Neuropsychiatr Genet 147B(8):1345-1354. https://doi.org/10.1002/ajmg.b.30867

Lau T, Schneidt T, Heimann F, Gundelfinger ED, Schloss P (2010) Somatodendritic serotonin release and re-uptake in mouse embryonic stem cell-derived serotonergic neurons. Neurochem Int 57(8):969-978. https://doi.org/10.1016/j.neuint.2010.10.003

Lesch KP, Waider J (2012) Serotonin in the modulation of neural plasticity and networks: implications for neurodevelopmental disorders. Neuron 76(1):175-191. https://doi.org/10.1016/j.neuro n.2012.09.013

Lesch KP, Timmesfeld N, Renner TJ, Halperin R, Roser C, Nguyen TT, Craig DW, Romanos J, Heine M, Meyer J, Freitag C, Warnke
A, Romanos M, Schafer H, Walitza S, Reif A, Stephan DA, Jacob C (2008) Molecular genetics of adult ADHD: converging evidence from genome-wide association and extended pedigree linkage studies. J Neural Transm 115(11):1573-1585. https://doi. org/10.1007/s00702-008-0119-3

Lesch KP, Selch S, Renner TJ, Jacob C, Nguyen TT, Hahn T, Romanos M, Walitza S, Shoichet S, Dempfle A, Heine M, Boreatti-Hummer A, Romanos J, Gross-Lesch S, Zerlaut H, Wultsch T, Heinzel S, Fassnacht M, Fallgatter A, Allolio B, Schafer H, Warnke A, Reif A, Ropers HH, Ullmann R (2011) Genome-wide copy number variation analysis in attention-deficit/hyperactivity disorder: association with neuropeptide $\mathrm{Y}$ gene dosage in an extended pedigree. Mol Psychiatry 16(5):491-503. https://doi.org/10.1038/ mp.2010.29

Li YQ, Li H, Kaneko T, Mizuno N (2001) Morphological features and electrophysiological properties of serotonergic and nonserotonergic projection neurons in the dorsal raphe nucleus. An intracellular recording and labeling study in rat brain slices. Brain Res 900(1):110-118

Lissemore JI, Sookman D, Gravel P, Berney A, Barsoum A, Diksic M, Nordahl TE, Pinard G, Sibon I, Cottraux J, Leyton M, Benkelfat C (2018) Brain serotonin synthesis capacity in obsessivecompulsive disorder: effects of cognitive behavioral therapy and sertraline. Trans Psychiatry 8(1):82. https://doi.org/10.1038/s4139 8-018-0128-4

Lu J, Zhong X, Liu H, Hao L, Huang CT, Sherafat MA, Jones J, Ayala M, Li L, Zhang SC (2016) Generation of serotonin neurons from human pluripotent stem cells. Nat Biotechnol 34(1):89-94. https ://doi.org/10.1038/nbt.3435

Marazziti D (2017) Understanding the role of serotonin in psychiatric diseases. F1000Research 6:180-180. https://doi.org/10.12688/ f1000research.10094.1

Mariani J, Coppola G, Zhang P, Abyzov A, Provini L, Tomasini L, Amenduni M, Szekely A, Palejev D, Wilson M, Gerstein M, Grigorenko EL, Chawarska K, Pelphrey KA, Howe JR, Vaccarino FM (2015) FOXG1-dependent dysregulation of GABA/ glutamate neuron differentiation in autism spectrum disorders. Cell 162(2):375-390. https://doi.org/10.1016/j.cell.2015.06.034

McNeill RV, Ziegler GC, Radtke F, Nieberler M, Lesch KP, Kittel-Schneider S (2020) Mental health dished up-the use of iPSC models in neuropsychiatric research. J Neural Transm (Vienna). https:// doi.org/10.1007/s00702-020-02197-9

Merkle FT, Maroof A, Wataya T, Sasai Y, Studer L, Eggan K, Schier AF (2015) Generation of neuropeptidergic hypothalamic neurons from human pluripotent stem cells. Development 142(4):633-643. https://doi.org/10.1242/dev.117978

Mlinar B, Montalbano A, Baccini G, Tatini F, Berlinguer Palmini R, Corradetti R (2015) Nonexocytotic serotonin release tonically suppresses serotonergic neuron activity. J Gen Physiol 145(3):225251. https://doi.org/10.1085/jgp.201411330

Monti JM, Jantos H (2008) The roles of dopamine and serotonin, and of their receptors, in regulating sleep and waking. Prog Brain Res 172:625-646. https://doi.org/10.1016/s0079-6123(08)00929-1

Muzerelle A, Scotto-Lomassese S, Bernard JF, Soiza-Reilly M, Gaspar $\mathrm{P}$ (2016) Conditional anterograde tracing reveals distinct targeting of individual serotonin cell groups (B5-B9) to the forebrain and brainstem. Brain Struct Funct 221(1):535-561. https://doi. org/10.1007/s00429-014-0924-4

Neale BM, Medland S, Ripke S, Anney RJ, Asherson P, Buitelaar J, Franke B, Gill M, Kent L, Holmans P, Middleton F, Thapar A, Lesch KP, Faraone SV, Daly M, Nguyen TT, Schafer H, Steinhausen HC, Reif A, Renner TJ, Romanos M, Romanos J, Warnke A, Walitza S, Freitag C, Meyer J, Palmason H, Rothenberger A, Hawi Z, Sergeant J, Roeyers H, Mick E, Biederman J (2010) Case-control genome-wide association study of attention-deficit/ 
hyperactivity disorder. J Am Acad Child Adolesc Psychiatry 49(9):906-920. https://doi.org/10.1016/j.jaac.2010.06.007

Niederkofler V, Asher TE, Dymecki SM (2015) Functional interplay between dopaminergic and serotonergic neuronal systems during development and adulthood. ACS Chem Neurosci 6(7):10551070. https://doi.org/10.1021/acschemneuro.5b00021

Norton WH, Folchert A, Bally-Cuif L (2008) Comparative analysis of serotonin receptor (HTR1A/HTR1B families) and transporter (slc6a4a/b) gene expression in the zebrafish brain. J Comp Neurol 511(4):521-542. https://doi.org/10.1002/cne.21831

Oades RD (2008) Dopamine-serotonin interactions in attention-deficit hyperactivity disorder (ADHD). Prog Brain Res 172:543-565. https://doi.org/10.1016/s0079-6123(08)00926-6

Ovesny M, Krizek P, Borkovec J, Svindrych Z, Hagen GM (2014) ThunderSTORM: a comprehensive ImageJ plug-in for PALM and STORM data analysis and super-resolution imaging. Bioinformatics 30(16):2389-2390. https://doi.org/10.1093/bioinforma tics/btu202

Pauly MG, Krajka V, Stengel F, Seibler P, Klein C, Capetian P (2018) Adherent vs free-floating neural induction by dual SMAD inhibition for neurosphere cultures derived from human induced pluripotent stem cells. Front Cell Dev Biol. https://doi.org/10.3389/ fcell.2018.00003

Quentin E, Belmer A, Maroteaux L (2018) Somato-dendritic regulation of raphe serotonin neurons; a key to antidepressant action. Front Neurosci 12:982. https://doi.org/10.3389/fnins.2018.00982

Saigal N, Bajwa AK, Faheem SS, Coleman RA, Pandey SK, Constantinescu CC, Fong V, Mukherjee J (2013) Evaluation of serotonin 5 -HT(1A) receptors in rodent models using $\left[{ }^{18} \mathrm{~F}\right]$ mefway PET. Synapse 67(9):596-608. https://doi.org/10.1002/syn.21665

Sanchez-Danes A, Consiglio A, Richaud Y, Rodriguez-Piza I, Dehay B, Edel M, Bove J, Memo M, Vila M, Raya A, Izpisua Belmonte JC (2012) Efficient generation of A9 midbrain dopaminergic neurons by lentiviral delivery of LMX1A in human embryonic stem cells and induced pluripotent stem cells. Hum Gene Ther 23(1):56-69. https://doi.org/10.1089/hum.2011.054

Sanders SJ, Ercan-Sencicek AG, Hus V, Luo R, Murtha MT, MorenoDe-Luca D, Chu SH, Moreau MP, Gupta AR, Thomson SA, Mason CE, Bilguvar K, Celestino-Soper PB, Choi M, Crawford EL, Davis L, Wright NR, Dhodapkar RM, DiCola M, DiLullo NM, Fernandez TV, Fielding-Singh V, Fishman DO, Frahm S, Garagaloyan R, Goh GS, Kammela S, Klei L, Lowe JK, Lund SC, McGrew AD, Meyer KA, Moffat WJ, Murdoch JD, O'Roak BJ, Ober GT, Pottenger RS, Raubeson MJ, Song Y, Wang Q, Yaspan BL, Yu TW, Yurkiewicz IR, Beaudet AL, Cantor RM, Curland M, Grice DE, Gunel M, Lifton RP, Mane SM, Martin DM, Shaw CA, Sheldon M, Tischfield JA, Walsh CA, Morrow EM, Ledbetter DH, Fombonne E, Lord C, Martin CL, Brooks AI, Sutcliffe JS, Cook EH Jr, Geschwind D, Roeder K, Devlin B, State MW (2011) Multiple recurrent de novo CNVs, including duplications of the $7 q 11.23$ Williams syndrome region, are strongly associated with autism. Neuron 70(5):863-885. https://doi.org/10.1016/j.neuro n.2011.05.002

Sanders SJ, He X, Willsey AJ, Ercan-Sencicek AG, Samocha KE, Cicek AE, Murtha MT, Bal VH, Bishop SL, Dong S, Goldberg AP, Jinlu C, Keaney JF 3rd, Klei L, Mandell JD, Moreno-De-Luca D, Poultney CS, Robinson EB, Smith L, Solli-Nowlan T, Su MY, Teran NA, Walker MF, Werling DM, Beaudet AL, Cantor RM, Fombonne E, Geschwind DH, Grice DE, Lord C, Lowe JK, Mane SM, Martin DM, Morrow EM, Talkowski ME, Sutcliffe JS, Walsh CA, Yu TW, Ledbetter DH, Martin CL, Cook EH, Buxbaum JD, Daly MJ, Devlin B, Roeder K, State MW (2015) Insights into autism spectrum disorder genomic architecture and biology from 71 Risk Loci. Neuron 87(6):1215-1233. https://doi.org/10.1016/j. neuron.2015.09.016
Schneider CA, Rasband WS, Eliceiri KW (2012) NIH Image to ImageJ: 25 years of image analysis. Nat Methods 9(7):671-675

Shi Y, Kirwan P, Livesey FJ (2012) Directed differentiation of human pluripotent stem cells to cerebral cortex neurons and neural networks. Nat Protoc 7(10):1836-1846. https://doi.org/10.1038/nprot .2012 .116

Siuta MA, Robertson SD, Kocalis H, Saunders C, Gresch PJ, Khatri V, Shiota C, Kennedy JP, Lindsley CW, Daws LC, Polley DB, Veenstra-Vanderweele J, Stanwood GD, Magnuson MA, Niswender KD, Galli A (2010) Dysregulation of the norepinephrine transporter sustains cortical hypodopaminergia and schizophrenia-like behaviors in neuronal rictor null mice. PLoS Biol 8(6):e1000393. https://doi.org/10.1371/journal.pbio.1000393

Somers A, Jean JC, Sommer CA, Omari A, Ford CC, Mills JA, Ying L, Sommer AG, Jean JM, Smith BW, Lafyatis R, Demierre MF, Weiss DJ, French DL, Gadue P, Murphy GJ, Mostoslavsky G, Kotton DN (2010) Generation of transgene-free lung disease-specific human induced pluripotent stem cells using a single excisable lentiviral stem cell cassette. Stem Cells 28(10):1728-1740. https ://doi.org/10.1002/stem.495

Suzuki S, Akamatsu W, Kisa F, Sone T, Ishikawa KI, Kuzumaki N, Katayama H, Miyawaki A, Hattori N, Okano H (2017) Efficient induction of dopaminergic neuron differentiation from induced pluripotent stem cells reveals impaired mitophagy in PARK2 neurons. Biochem Biophys Res Commun 483(1):88-93. https://doi. org/10.1016/j.bbrc.2016.12.188

Tao-Cheng JH, Thein S, Yang Y, Reese TS, Gallant PE (2014) Homer is concentrated at the postsynaptic density and does not redistribute after acute synaptic stimulation. Neuroscience 266:80-90. https://doi.org/10.1016/j.neuroscience.2014.01.066

Tofoli FA, Semeano ATS, Oliveira-Giacomelli A, Goncalves MCB, Ferrari MFR, Veiga Pereira L, Ulrich H (2019) Midbrain dopaminergic neurons differentiated from human-induced pluripotent stem cells. Methods Mol Biol 1919:97-118. https://doi. org/10.1007/978-1-4939-9007-8_8

Treutlein J, Cichon S, Ridinger M, Wodarz N, Soyka M, Zill P, Maier W, Moessner R, Gaebel W, Dahmen N, Fehr C, Scherbaum N, Steffens M, Ludwig KU, Frank J, Wichmann HE, Schreiber S, Dragano N, Sommer WH, Leonardi-Essmann F, Lourdusamy A, Gebicke-Haerter P, Wienker TF, Sullivan PF, Nothen MM, Kiefer F, Spanagel R, Mann K, Rietschel M (2009) Genomewide association study of alcohol dependence. Arch Gen Psychiatry 66(7):773-784. https://doi.org/10.1001/archgenpsychiat ry. 2009.83

Uhl GR, Drgon T, Liu QR, Johnson C, Walther D, Komiyama T, Harano M, Sekine Y, Inada T, Ozaki N, Iyo M, Iwata N, Yamada M, Sora I, Chen CK, Liu HC, Ujike H, Lin SK (2008) Genomewide association for methamphetamine dependence: convergent results from 2 samples. Arch Gen Psychiatry 65(3):345-355. https ://doi.org/10.1001/archpsyc.65.3.345

Vadodaria KC, Mertens J, Paquola A, Bardy C, Li X, Jappelli R, Fung L, Marchetto MC, Hamm M, Gorris M, Koch P, Gage FH (2016) Generation of functional human serotonergic neurons from fibroblasts. Mol Psychiatry 21(1):49-61. https://doi.org/10.1038/ mp.2015.161

Vadodaria KC, Ji Y, Skime M, Paquola AC, Nelson T, Hall-Flavin D, Heard KJ, Fredlender C, Deng Y, Elkins J, Dani K, Le AT, Marchetto MC, Weinshilboum R, Gage FH (2019) Altered serotonergic circuitry in SSRI-resistant major depressive disorder patient-derived neurons. Mol Psychiatry 24(6):808-818. https:// doi.org/10.1038/s41380-019-0377-5

van de Linde S, Loschberger A, Klein T, Heidbreder M, Wolter S, Heilemann M, Sauer M (2011) Direct stochastic optical reconstruction microscopy with standard fluorescent probes. Nat Protoc 6(7):991-1009. https://doi.org/10.1038/nprot.2011.336 
Vandermaelen CP, Aghajanian GK (1983) Electrophysiological and pharmacological characterization of serotonergic dorsal raphe neurons recorded extracellularly and intracellularly in rat brain slices. Brain Res 289(1-2):109-119

Verheij MMM, Contet C, Karel P, Latour J, van der Doelen RHA, Geenen B, van Hulten JA, Meyer F, Kozicz T, George O, Koob GF, Homberg JR (2018) Median and dorsal raphe serotonergic neurons control moderate versus compulsive cocaine intake. Biol Psychiatry 83(12):1024-1035. https://doi.org/10.1016/j.biops ych.2017.10.031

Vizi ES, Kiss JP, Lendvai B (2004) Nonsynaptic communication in the central nervous system. Neurochem Int 45(4):443-451. https ://doi.org/10.1016/j.neuint.2003.11.016

Waider J, Popp S, Lange MD, Kern R, Kolter JF, Kobler J, Donner NC, Lowe KR, Malzbender JH, Brazell CJ, Arnold MR, Aboagye B, Schmitt-Bohrer A, Lowry CA, Pape HC, Lesch KP (2017) Genetically driven brain serotonin deficiency facilitates panic-like escape behavior in mice. Transl Psychiatry 7(10):e1246. https:// doi.org/10.1038/tp.2017.209

Wang K, Zhang H, Ma D, Bucan M, Glessner JT, Abrahams BS, Salyakina D, Imielinski M, Bradfield JP, Sleiman PMA, Kim CE, Hou C, Frackelton E, Chiavacci R, Takahashi N, Sakurai T, Rappaport E, Lajonchere CM, Munson J, Estes A, Korvatska O, Piven J, Sonnenblick LI, Alvarez Retuerto AI, Herman EI, Dong H, Hutman T, Sigman M, Ozonoff S, Klin A, Owley T, Sweeney JA, Brune CW, Cantor RM, Bernier R, Gilbert JR, Cuccaro ML, McMahon WM, Miller J, State MW, Wassink TH, Coon
H, Levy SE, Schultz RT, Nurnberger JI, Haines JL, Sutcliffe JS, Cook EH, Minshew NJ, Buxbaum JD, Dawson G, Grant SFA, Geschwind DH, Pericak-Vance MA, Schellenberg GD, Hakonarson H (2009) Common genetic variants on 5p14.1 associate with autism spectrum disorders. Nature 459(7246):528-533. https:// doi.org/10.1038/nature07999

Wegel E, Gohler A, Lagerholm BC, Wainman A, Uphoff S, Kaufmann R, Dobbie IM (2016) Imaging cellular structures in super-resolution with SIM, STED and localisation microscopy: a practical comparison. Sci Rep 6:27290. https://doi.org/10.1038/srep27290

Wong PT, Feng H, Teo WL (1995) Interaction of the dopaminergic and serotonergic systems in the rat striatum: effects of selective antagonists and uptake inhibitors. Neurosci Res 23(1):115-119

Yang N, Chanda S, Marro S, Ng YH, Janas JA, Haag D, Ang CE, Tang Y, Flores Q, Mall M, Wapinski O, Li M, Ahlenius H, Rubenstein JL, Chang HY, Buylla AA, Sudhof TC, Wernig M (2017) Generation of pure GABAergic neurons by transcription factor programming. Nat Methods 14(6):621-628. https://doi.org/10.1038/ nmeth.4291

Zhang Z-W (2003) Serotonin induces tonic firing in layer v pyramidal neurons of rat prefrontal cortex during postnatal development. J Neurosci 23(8):3373-3384. https://doi.org/10.1523/jneurosci.2308-03373.2003

Publisher's Note Springer Nature remains neutral with regard to jurisdictional claims in published maps and institutional affiliations.

\section{Authors and Affiliations}

\section{Charline Jansch ${ }^{1}$ - Georg C. Ziegler ${ }^{1,2}$ - Andrea Forero ${ }^{1} \cdot$ Sina Gredy $^{3,4} \cdot$ Sina Wäldchen $^{5} \cdot$ Maria Rosaria Vitale $^{1,4}$. Evgeniy Svirin ${ }^{1,4}$. Johanna E. M. Zöller ${ }^{1,6}$. Jonas Waider ${ }^{1} \cdot$ Katharina Günther $^{7,8} \cdot$ Frank Edenhofer $^{7} \cdot$ Markus Sauer $^{5}$. Erhard Wischmeyer ${ }^{1,3} \cdot$ Klaus-Peter Lesch ${ }^{1,4,6}$}

1 Division of Molecular Psychiatry, Center of Mental Health, University of Würzburg, Margarete-Höppel-Platz 1, 97080 Würzburg, Germany

2 Department of Psychiatry, Psychosomatics and Psychotherapy, Center of Mental Health, University of Würzburg, Würzburg, Germany

3 Institute of Physiology, Molecular Electrophysiology, University of Würzburg, Würzburg, Germany

4 Laboratory of Psychiatric Neurobiology, Institute of Molecular Medicine, Sechenov First Moscow State Medical University, Moscow, Russia
5 Department of Biotechnology and Biophysics, Biocenter, University of Würzburg, Würzburg, Germany

6 Department of Translational Neuroscience, School for Mental Health and Neuroscience (MHeNS), Maastricht University, Maastricht, The Netherlands

7 Department of Genomics, Stem Cell Biology and Regenerative Medicine, Institute of Molecular Biology and CMBI, Leopold-Franzens-University Innsbruck, Innsbruck, Austria

8 Institute of Molecular Regenerative Medicine, SCI-TReCS, Paracelsus Medical University, Salzburg, Austria 